\title{
Analysis of major sperm proteins in two nematode species from two classes, Enoplus brevis (Enoplea, Enoplida) and Panagrellus redivivus (Chromadorea, Rhabditida), reveal similar localization, but less homology of protein sequences than expected for Nematoda phylum
}

Julia K. Zograf

A.V. Zhirmunsky National Scientific Center of Marine Biology FEB RAS Yulia A. Trebukhova

A.V. Zhirmunsky National Scientific Center of Marine Biology FEB RAS

Vladimir V. Yushin

A.V. Zhirmunsky National Scientific Center of Marine Biology FEB RAS

Konstantin V. Yakovlev ( $\square$ konstantin.yakov@gmail.com )

A.V. Zhirmunsky National Scientific Center of Marine Biology FEB RAS https://orcid.org/0000-00020718-0775

Original Article

Keywords: Chromadorea, Enoplea, evolution, MSP, Nematoda, spermatozoa

Posted Date: February 9th, 2021

DOI: https://doi.org/10.21203/rs.3.rs-172088/v1

License: (1) This work is licensed under a Creative Commons Attribution 4.0 International License.

Read Full License

Version of Record: A version of this preprint was published at Organisms Diversity \& Evolution on September 20th, 2021. See the published version at https://doi.org/10.1007/s13127-021-00522-y. 


\section{Analysis of major sperm proteins in two nematode species from two classes,}

2 Enoplus brevis (Enoplea, Enoplida) and Panagrellus redivivus (Chromadorea,

6 Julia K. Zograf ${ }^{1}$, Yulia A. Trebukhova ${ }^{2}$, Vladimir V. Yushin ${ }^{1}$, Konstantin V.

7 Yakovlev $^{3 *}$

8

$9 \quad{ }^{1}$ Laboratory of Embryology, A.V. Zhirmunsky National Scientific Center of Marine Biology, Far

10 Eastern Branch, Russian Academy of Sciences, Vladivostok, Russia.

$11{ }^{2}$ Laboratory of Systematics and Morphology, A.V. Zhirmunsky National Scientific Center of

12 Marine Biology, Far Eastern Branch, Russian Academy of Sciences, Vladivostok, Russia.

$13{ }^{3}$ Laboratory of Cytotechnology, A.V. Zhirmunsky National Scientific Center of Marine Biology,

14 Far Eastern Branch, Russian Academy of Sciences, Vladivostok, Russia.

15

16 Vladimir V. Yushin and Konstantin V. Yakovlev contributed equally to this work

17

18

19

20

Julia Zograf https://orcid.org/0000-0002-4723-7078

22 Yulia Trebukhova https://orcid.org/0000-0003-0538-6005

23 Vladimir Yushin https://orcid.org/0000-0002-0622-3112

Konstantin Yakovlev https://orcid.org/0000-0002-0718-0775 


\section{Abstract}

27 Major sperm proteins (MSP) are a nematode-specific system of motor proteins required for

28 amoeboid sperm movement. A number of MSP genes vary in different nematode species, but encoded protein sequences reveal high homology between these proteins. In fact, all studies of MSPs localization and functions are based exclusively on the representatives of the order 31 Rhabditida belonging to the nematode class Chromadorea, while MSP-driven sperm movement in

32 Enoplea, another major clade of the phylum Nematoda is still unconfirmed. In this study, we found out the presence of MSPs in the enoplean nematode Enoplus brevis (Enoplida) and compared MSP localization in sperm of this species with the chromadorean nematode Panagrellus redivivus (Rhabditida). Then, we analyzed the putative MSP sequences of both species. Our results indicate that MSPs are presented in E. brevis spermatozoa and form filamentous structures after sperm activation, which may be considered as the evidence of their motor functions similar to those in the spermatozoa of chromadorean nematodes. We found that E. brevis MSPs show lower homology to known proteins of rhabditids which species reveal hyper-conservatism in MSP protein sequences. It reflects evidently more distant evolutionary relationships of Enoplea and 41 Chromadorea than exist within Rhabditida order. Our data denote necessity of reconsideration of view on MSP evolution within Nematoda.

43 Keywords Chromadorea $\cdot$ Enoplea $\cdot$ evolution $\cdot$ MSP $\cdot$ Nematoda $\cdot$ spermatozoa

Acknowledgments The authors are grateful to staff of the Far Eastern Center of Electron Microscopy (NSCMB FEB RAS) for their assistance in imaging. The authors are also grateful to staff of White Sea Biological Station for the help in E. brevis collection.

49 Funding information This study was supported by Russian Foundation for Basic Research (Grants No. 17-04-00719-a and 14-04-00334-a). 
52 Data availability statement Nucleotide sequences coding E. brevis MSP124-1, MSP124-2 and

53 MSP124-3 were deposited to the Third Party Annotation Section of the DDBJ/ENA/GenBank

54 databases under the accession numbers TPA: BK014294-BK014296..

55

56 Conflict of interest The authors declare that they have no conflict of interest. 


\section{Introduction}

59 Nematodes are one of several animal groups which spermatozoa are amoeboid cells devoid of

60 flagella (Morrow 2004). Nematode spermatozoa accumulated in the seminal vesicles of males are non-motile cells and may be considered as immature spermatozoa because the final step of spermiogenesis proceeds only after insemination and activation in the female gonoduct where spermatozoa are drastically transformed into pseudopod bearing motile cells termed as mature spermatozoa (Shepherd 1981).

The amoeboid mature spermatozoa move by crawling which resembles amoeboid motility in other eukaryotic cells including some aflagellate spermatozoa. Instead of actin, motility of nematode sperm is driven by unique motor system based on the major sperm protein (MSP) filaments (Roberts and Stewart 2012). Molecular machinery of nematode sperm crawling wellstudied in Ascaris suum and Caenorhabditis elegans (Smith 2014) is similar to actin-based amoeboid movement (Ryan et al. 2012). A basis of this movement is assembly-disassembly of MSP filaments in pseudopod, where MSP is accumulated after spermatozoon activation and forms long multi-filament fibers (King et al. 1994). MSP filaments assemble preferentially at the leading edge of the sperm pseudopod and are organized into long, multi-filament fiber complexes. These filamentous arrays are linked to the pseudopod plasma membrane and extend back to the junction between the cell body and pseudopod. As sperm crawl forward, these complexes flow back towards the cell body due to filaments assembly at the leading edge and disassembly at the rear of the pseudopod (King et al. 1994; Sepsenwol et al. 1989). Both processes are tightly regulated by set of cytosolic, membrane and MSP filament-associated proteins (Ellis and Stanfield 2014; Roberts and Stewart 2000; Singaravelu and Singson 2011; Smith 2014). Although many proteins with MSP domain persist in plants, fungi and other animals (Tarr and Scott 2005) motor functions of MSPs have been found only in nematode sperm. Motor (cytoskeletal) MSPs conserved between nematode species consist of 126-127 amino acids and detected as small 14-17-kDa proteins (Höglund et al. 2008; King et al. 1992; Klass and Hirsh 1981; Strube et al. 2009). 
The classification based on morphological and molecular data subdivides the phylum

85 Nematoda into two classes Enoplea and Chromadorea (Fig. 1) (De Ley and Blaxter 2002). The

latter comprises seven orders where the movement of spermatozoa have been observed and studied

in details in the most diverse order Rhabditida due to the free-living soil nematode C. elegans and several parasitic taxa including Ascaris. The MSPs as the nematode-specific cytoskeleton proteins or MSP-coding genes have also been found in all tested species of the order Rhabditida (Fig. 1). Within this order, MSP identity of amino acid sequences is over $80 \%$ between species (Kasimatis and Phillips 2018; Scott et al. 1989). In representatives of other orders of Chromadorea amoeboid movement of spermatozoa confirmed by development of prominent pseudopods filled with cytoskeleton fibers reminding well cytoskeleton of pseudopods in rhabditids (Justine 2002; Yushin and Malakhov 2014). We assume that the amoeboid movement based on MSP fibers is characteristic for entire class Chromadorea.

Another nematode class Enoplea includes two well defined subclasses Dorylaimia and Enoplia (De Ley and Blaxter 2002). In the representatives of Dorylaimia amoeboid spermatozoa with pseudopods filled with cytoskeleton fibers have been described in many taxa (Justine 2002; Yushin and Malakhov 2014). This specific morphology of motile sperm is confirmed by direct observation of sperm movement in the dorylaimian Gastromermis sp (order Mermithida) (Poinar and Hess-Poinar 1993). However, analysis of genome of the dorylaimian Trichinella spiralis (Trichinellida) did not show the presence of presumptive amino acid sequences with great similarity to spermatozoan MSPs of rhabditids (Kasimatis and Phillips 2018). So, proteins driving ameboid movement of sperm in species of Dorylaimia are still undetermined.

The representatives of Enoplida have plesiomorphic features such as nuclear envelope in spermatozoan nucleus, early indeterminate cleavage, late establishment of bilateral symmetry, late separation of the germ line, absence of eutely (cell constancy), capability to limited regeneration, absence of distal tip cell in gonads (Felix 2004; Joshi and Rothman 2005; Malakhov 1994, 1998; Rusin and Malakhov 1998; Schulze and Schierenberg 2011; Voronov 1999; Voronov and Panchin 
110 1998; Yushin et al. 2014; Yushin and Malakhov 2004). Basal position of Enoplida is confirmed

111 also by latest molecular phylogenetic analyses of nematode relationships (Bik et al. 2010; Blaxter

112 and Koutsovoulos 2015; Holterman et al. 2006; Smythe et al. 2019; van Megen et al. 2009).

113 The subclass Enoplia includes taxa where characteristic pseudopod bearing spermatozoa

114 also have been described (Justine 2002; Lak et al. 2015; Yushin and Malakhov 2014). The

115 spermatozoa of nematodes of the genus Enoplus (order Enoplida) are amoeboid cells moving by

116 crawling; as in many other nematodes they are subdivided into posterior main cell body and 117 anterior pseudopod filled with cytoskeleton fibers (Yushin and Malakhov 1994). Similar 118 morphology and behavior of Enoplus sperm may points to the presence of similar motor proteins,

119 like MSPs. Nevertheless, as in the case of Dorylaimia, it is still unclear whether MSPs underlie 120 sperm crawling in Enoplia.

121 The goal of this study is to define the presence of MSP in Enoplia, and estimate possible 122 motor functions of MSP in this taxon. In this issue, we analyzed the presence of MSP and its 123 localization in spermatozoa of the marine enoplean species Enoplus brevis Bastian, 1865 124 (Enoplida) and compared results with MSP protein sequences and localization in the 125 chromadorean nematode Panagrellus redivivus Linnaeus, 1767 (Rhabditida), the species which 126 has typical spermatozoan morphology (Zograf 2014) and genome of which contains several MSP 127 genes (Scott et al., 1989; Srinivasan et al., 2013). Our choice of this representative of Chromadorea as reference species is also based on the ability of $P$. redivivus mature spermatozoa for conjugation in female gonoduct with formation of characteristic sperm chains (Zograf 2014). These chains can

130 be easily isolated from inseminated females for convenient observations of mature spermatozoa.

131 Next, to estimate phylogenetic relationships of both P. redivivus and E. brevis MSPs we 132 carried out phylogenetic analysis using MSP protein sequences of both taxa and available 133 sequences in databases of several Rhabditida and Dorylimia MSPs. By using anti-MSP antibodies, 134 we revealed that MSPs in cases of E. brevis and P. redivivus are cytoskeletal proteins that undergo 135 reorganization during maturation that led to formation of MSP fibers in mature sperm. Then, based 
136 on antigen sequence used for antibody generation we found mRNA possibly encoding cytoskeletal

137 MSP in E. brevis transcriptome. We conclude that E. brevis spermatozoa have MSP and its amino

138 acid sequence is similar to P. redivivus and C. elegans MSPs (75\% and 72\%, respectively). Here,

139 our results demonstrate that sperm of nematode E. brevis have MSPs, but their amino acid

140 sequences are less similar than between Rhabditida species. Thus, we conclude that within the

141 Nematoda phylum MSPs may more rapidly evolve in their protein sequences than expected, but it

142 does not lead to loss of their motor function.

143

144 Materials and methods

145 Animals

146 P. redivivus cultures were kept in oatmeal and bread-based medium with addition bakery yeasts.

147 Adult males and females of E. brevis were obtained from sand collected in the intertidal zone at

148 White Sea Biological Station of Lomonosov Moscow State University (Kandalaksha Bay, White 149 Sea).

150

151 Production of anti-MSP antibodies

152 Polyclonal anti-MSP antibodies were raised in rabbits against synthetic peptide 153 IKTTNMKRLGVDPPCGVLDPKE, which corresponds to part of the MSP domain of several 154 Rhabditida species, like C. elegans and Onchocerca volvulus (GenBank accession numbers 155 CCD73220.1 and AAA29421.1, respectively). For immunization synthetized peptide was 156 conjugated with keyhole limpet hemocyanin (KLH). Then antibodies were purified using antigenic 157 peptide by affinity chromatography. All procedures of antibody production were made in Cytokine 158 company (St. Petersburg, Russia).

160 SDS-electrophoresis and Western blot analysis 
161 Animals were frozen at $-80^{\circ} \mathrm{C}$ in minimal volume of $20 \mathrm{mM}$ potassium phosphate buffer with 100

$162 \mathrm{mM} \mathrm{NaCl}\left(\mathrm{pH}\right.$ 5.7) (P. redivivus) or $\mathrm{Ca}^{2+}, \mathrm{Mg}^{2+}$-free salt solution (CMFSS) (E. brevis). Samples

163 were thawed out, briefly homogenized in Sample buffer and boiled. Samples were resolved with 10\% (tubulin detection), 12\% (E. brevis, MSP detection) and 14\% (P. redivivus, MSP detection) SDS-PAGE and transferred to PVDF membrane. Membranes were incubated with $4 \%$ milk in PBST (PBS with $0.05 \%$ Tween 20) for $1 \mathrm{~h}$ and then with primary antibodies diluted with $1 \%$ milk

167 overnight at $4^{\circ} \mathrm{C}$. Monoclonal mouse anti- $\alpha$-tubulin antibody (clone DM1A, Sigma-Aldrich, 168 USA) was used at 1:10000 dilution. Rabbit anti-MSP antibodies were used at concentrations 0.24 $169 \mathrm{ug} / \mathrm{ml}$ for $P$. redivivus and $1.6 \mathrm{ug} / \mathrm{ml}$ for E. brevis. After washing membranes were incubated with HRP-conjugated goat anti-rabbit (1:5000 dilution, PI-1000, Vector Laboratories, USA) and antimouse antibodies (1:5000 dilution, PI-2000, Vector Laboratories, USA) for $1 \mathrm{~h}$. Then, membranes

172 were washed with PBST and PBS and then developed with Clarity Western ECL Substrate (Bio-

173 Rad, USA). To perform peptide competition assay, 2.25 ug of anti-MSP antibodies were incubated with $10 \mathrm{ug}$ of the synthetic peptide overnight at $4^{\circ} \mathrm{C}$, centrifuged at $10000 \mathrm{xg}$ for $15 \mathrm{~min}$ and then used with E. brevis samples.

\section{Immunofluorescence and imaging}

178 Immunostaining procedure was performed on sperm isolated by dissection from males and mated females. Adult $P$. redivivus were directly dissected on poly-L-lysine-coated slides in PBS and then

180 incubated for $10 \mathrm{~min}$ for binding extracted sperm to slides. E. brevis were dissected on poly-L181 lysine-coated slides in filtered sea water. All samples were fixed with 4\% PFA in PBS for 30 min.

182 Slides were rinsed with PBS, permeabilized 0.1\% Triton X-100 for 20 min and then blocked with $1831 \%$ normal goat serum and $1 \%$ BSA in washing buffer $(0.01 \%$ Tween 20, PBS $)$ for $2 \mathrm{~h}$. Samples were incubated with anti-MSP antibodies $(2.4 \mathrm{ug} / \mathrm{ml}$ for $P$. redivivus, $12 \mathrm{ug} / \mathrm{ml}$ for E. brevis) overnight at $4^{\circ} \mathrm{C}$. After washing slides were incubated with secondary goat anti-rabbit antibodies 
187 were stained with DAPI $(2 \mu \mathrm{g} / \mathrm{ml})$ for $20 \mathrm{~min}$. Slides were rinsed with PBS and mounted in

188 Vectashield medium (Vector Laboratories, Burlingame, CA, USA). Fluorescent images were

189 taken using LSM 510 Meta and LSM 780 confocal microscopes (Carl Zeiss, Jena, Germany) and 190 processed using ImageJ software (National Institutes of Health, USA).

192 Transcriptome assembly and phylogenetic analysis

193 E. brevis transcriptome was assembled using RNA-seq library available in GenBank (BioProject 194 PRJEB7588, SRA experiment accession number ERX616982) in Galaxy web-based platform 195 (https://usegalaxy.org) (Afgan et al. 2018). Initially, reads were filtered by quality (Filter by 196 quality option, quality cut-off: 20, minimum percentage: 90) and then by Trimmomatic (Bolger et 197 al. 2014). Filtered RNA-seq reads were used for de novo transcriptome assembly with Trinity with 198 default parameters (exceptions, minimum contig length: 250). Protein coding sequences were 199 extracted using TransDecoder (https://github.com/TransDecoder). MSP-domain proteins were 200 identified by Pfam search (El-Gebali et al. 2019).

201 Nucleotide sequences were aligned using MUSCLE (Edgar 2004). Protein sequences were 202 aligned using ProbCons (Do et al. 2005) and visualized in Jalview (Waterhouse et al. 2009). 203 Phylogenetic tree was created using maximum likelihood method with WAG substitution model 204 and branch support with SH-like aLRT (Shimodaira-Hasegawa-like approximate likelihood ratio 205 test). Multiple alignments and phylogenetic tree construction were done in Phylogeny.fr resource 206 (Dereeper et al. 2008).

208 Results

209 Localization of MSP in sperm

210 Firstly, we give data obtained on P. redivivus because this species has conserved MSPs that can 211 be detected by generated anti-MSP antibodies. In P. redivivus samples, Western Blot analysis 212 using generated anti-MSP antibodies showed two bands with approximate weight of 15 and 16 
$213 \mathrm{kDa}$ in both males and females, which is corresponds to mobility of nematode MSPs (Fig. 2). The

214 presence of MSP in female samples confirms that they include mated females bearing deposited

215 spermatozoa. Immunostaining of isolated spermatozoa revealed cytoplasmic localization of MSP.

216 In immature spermatozoa extracted from males, MSP localization is granular with highest signal

217 in cell periphery (Fig. 3a). Mature spermatozoa extracted from mated females were found as

218 conjugated into the chains (Fig. 3b). These chains supporting by tight contacts between

219 spermatozoa were earlier observed in the female gonoduct of $P$. redivivus and described by 220 transmission electron microscopy (Zograf 2014). Our results show that chains retain their 221 organization in PBS after dissection procedure. In activated spermatozoa, MSP localize 222 predominantly in well-defined pseudopodia, where MSP have granulo-fibrillar pattern (Fig. 3b). In E. brevis, anti-MSP antibodies detected a band with approximate size of 36-38 kDa (Fig.

224 4a), which is higher than known for MSPs in Rhabditida. Subsequent peptide competition assay 225 using peptide antigen showed significant reduction of the signal that confirm specificity of anti226 MSP reactivity in the case of the E. brevis samples (Fig. 4b). The presence of MSP in female 227 samples point to the presence of mature spermatozoa in uteri. Immunostaining of isolated 228 spermatozoa revealed different localizations. In immature spermatozoa, MSP was detected in 229 granules (Fig. 5a). Notably, incubation of spermatozoa in the sea water for 5-10 minutes led to re230 distribution of MSP toward more diffuse and filamentous manner in peripheral cytoplasm though 231 pseudopodia did not appear (Fig. 5b). Mature spermatozoa extracted from females had 232 pseudopodia where MSP now is localized (Fig. 5c).

234 Analysis of MSP sequences and phylogeny

235 For reasons given that the peptide antigen sequence is identical or highly homological to MSPs of 236 Rhabditida species, we decided to use its amino acid sequence to find MSP sequences of both $P$. 237 redivivus and $E$. brevis that potentially recognized by the generated antibodies. P. redivivus 238 putative protein sequences of MSPs are available and we used them in our analysis. Blast search 
239 using peptide antigen as a query in WormBase Parasite detected six most homologous putative 240 MSPs of $P$. redivivus consisting of 127 amino acids (Fig. 6a). These proteins are highly 241 homologous to each other with identity between them 94-99\%. Alignment of the found $P$. 242 redivivus MSPs with C. elegans one with accession number P53017 showed identity 87-90\%. In 243 our research we used generated transcriptome of E. brevis from available SRA data (ERX616982).

244 Blast search among putative proteins generated from the transcriptome with peptide antigen 245 sequence as query detected three 124-amino acid proteins called MSP124-1, MSP124-2 and 246 MSP124-3.

247 Independent Pfam search among putative protein sequences generated from whole 248 transcriptome attributed MSP124 proteins to MSP family. The presence of MSP124 transcripts 249 was validated by RT-PCR (Fig. S1). Primers and PCR conditions are shown in Table S1. Multiple 250 alignment of their coding mRNAs showed that these transcripts are highly homologous in their 251 coding regions and variable in untranslated regions (Fig. S2). Amino acid sequences of MSP1241, MSP124-2 and MSP124-3 are almost identical to each other (98-99\%) (Fig. 6b). Among proteins with MSP domain of E. brevis MSP124 is a group, which most homologous to sperm MSPs of Rhabditida. ExPASy calculations showed that all MSP124 are basic proteins with predicted weight $13.7 \mathrm{kDa}$ (https://web.expasy.org/compute_pi/) (Gasteiger et al. 2005). Predicted 256 molecular weight of MSP124 proteins did not conform with results of Western Blot, when molecular weight of E. brevis MSP was much higher than expected. Though, peptide competition assay showed specific binding of anti-MSP antibodies to this protein band (Fig. 4). So, we concluded that MSP124 proteins may have unusual mobility in SDS-PAGE conditions due to posttranslation modifications or some unknown features of these proteins. these proteins by multiple alignment and created phylogenetic tree. In this alignment, we used one 263 of six found P. redivivus MSPs (Pan_g9068.t1), all three MSP124 proteins of E. brevis and 264 available sequences of Rhabditida and Dorylaimia species. The latter were chosen as most 
265 homological proteins to C. elegans and P. redivivus (Trichuris trichiura, Trichinella nativa, $T$. 266 pseudospiralis and T. papuae) and subsequently selected by $\mathrm{pl}$ value ( $\mathrm{pl}>7)$ by ExPASy analysis, 267 because MSPs found in rhabditids are basic proteins. Multiple alignment, which has been done in 268 ProbCons, is given in Fig. 7a. MSP of $P$. redivivus related to that of Rhabditida with $88 \%$ identity 269 to C. elegans one. E. brevis MSP124 proteins have the same values of similarity to MSPs of $C$. 270 elegans (52\% identity and $72 \%$ similarity) and P. redivivus (55\% identity and $75 \%$ similarity). 271 Also, similarity between MSPs of Dorylaimia and Rhabditida taxa is $48-62 \%$, and similarity 272 between Dorylaimia taxa and E. brevis is $48-53 \%$. Between Dorylaimia species there is high 273 divergence in MSP sequences. Similar protein sequences can be found only within the same genus, 274 for example, in Trichinella (Fig. 7a, T. pseudospiralis and T. papuae). Unlike Rhabditida, different 275 genera of Dorylaimia, as Trichuris and Trichinella, do not have great homology among submitted 276 MSPs. Brief screening of available genomes of at least fourteen Dorylaimia species (WormBase 277 Parasite) showed that these species have also relatively distant MSPs to both Rhabditida and $E$. 278 brevis proteins (these sequences are not included in alignment). The presented alignment was 279 subsequently used as input for generation of Maximum likelihood phylogenetic tree (Fig. 7b). As 280 expected, $P$. redivius MSP is related to the Rhabditida proteins. The most interestingly that

281 Rhabditida and E. brevis MSPs form sister groups with significant SH-aLRT branch support 282 (0.84). Dorylaimia MSPs are located on different branches, and more careful phylogeny requires 283 more MSP sequences of this group.

\section{Discussion}

286 Aflagellate spermatozoa appeared independently during evolution in different metazoan taxa many 287 times. Nematoda and its sister group, Nematomorpha (horsehair worms), both produce aflagellate 288 spermatozoa (Schmidt-Rhaesa 1997/98). It is known that spermatozoa of nematodes locomote by 289 amoeboid movement, while spermatozoan motility in horsehair worms has not been described to 290 date. In the most cases, amoeboid motility is driven by actin polymerization or cortical actin- 
291 myosin contraction (Miyata et al. 2020). Numerous studies on Rhabditida, an order of the 292 nematode class Chromadorea, showed an existence of unique MSP-based sperm locomotion. MSP 293 protein sequences among Rhabditida, as previously noted, are highly conserved and many 294 researchers conclude that it is the case for the whole phylum Nematoda (Höglund et al. 2008; 295 Hojas and Post 2000; Scott et al. 1989). Kasimatis and Phillips (2018) proposed that conservation 296 of MSP sequences should be tightly evolutionary regulated, as nonsynonimous mutations lead to 297 lack or incorrect MSP filament assembly (del Castillo-Olivares and Smith 2008).

298 Nematodes can be found everywhere; they inhabit different ecological niches and comprise 299 both free-living and parasitic taxa. In spite of the great ecological and taxonomical diversity of 300 nematodes, it has been postulated that sequences of MSPs to be highly conserved. This suggestion 301 originates from the fact that all tested species, both free-living and parasitic, have highly similar 302 MSP protein sequences. The exception may be some parthenogenetic nematodes which MSPs 303 have not been found at protein level, though their genomes contain functional MSP genes (Heger 304 et al. 2010). Nevertheless, a hypothesis of MSP conservatism is based only on studies of species 305 belonging to one chromadorean order Rhabditida. Evidences that MSPs in another class of 306 nematodes, Enoplea, are identical over $80 \%$ to those of Rhabditida, have not been published to 307 date.

308 Important questions originate from the well-known MSP-based locomotion of spermatozoa 309 in rhabditids and the lack of direct evidences, whether Enoplea also use MSP machinery for sperm 310 movement. Does the origin of the MSP-based locomotion correlate with appearance of amoeboid311 moving sperm of nematodes? To answer to this question, it is necessary ascertain, whether MSP312 based sperm locomotion exists in species of the enoplean clades Enoplia and Dorylaimia. To 313 search for MSPs in E. brevis, we applied a comparative approach using P. redivivus, the Rhabditida 314 species, which sperm have MSP. This approach is a combination of the detection of MSPs by 315 antibodies and the subsequent search of genome- or transcriptome-encoded MSP sequences using 316 the antigenic peptide sequence as a query. 
Firstly, we tested the chosen approach on $P$. redivivus, which sperm cells is of typical 318 morphology for Rhabditida (Zograf 2014). MSP localization in P. redivivus showed that in the

319 round immature spermatozoa MSPs were found throughout cytoplasm with maximal signal in cell 320 periphery, while in the amoeboid mature spermatozoa MSPs mainly localized in pseudopodia.

321 These changes of MSP localization before and after sperm activation are typical for C. elegans 322 (Chu and Shakes 2013) and correlate with appearance of MSP fibers required for sperm movement 323 (Marcello et al. 2012). These data and finding presumptive encoded MSPs in genome, which are 324 highly homologous to those of other Rhabditida species, suggest that the $P$. redivivus spermatozoa use MSP-based movement.

Secondly, the used approach allowed us to detect MSPs in the spermatozoa of E. brevis and find out three MSP-coding sequences in transcriptome that we called MSP124-1, 2 and 3.

328 Despite the lack of functional analysis, we suggest that E. brevis MSPs are motor proteins because their intracellular localization changed after sperm activation toward formation of MSP fibers in a pseudopod, as it was demonstrated in spermatozoa of $P$. redivivus and other rhabditids (Yushin et al. 2016).

Our data show that the E. brevis MSP124 proteins are less homologous to MSPs of

333 Rhabditida. All three MSP124 proteins showed less similarity (identity and positive substitutions)

334 to those of C. elegans (72\%) and P. redivivus (75\%), than it is known for Rhabditida (83.5-97.7\%

335 identity between species) (Kasimatis and Phillips 2018). Our results showed that MSPs of the 336 representatives of all three subclasses, Enoplia, Dorylaimia and Rhabditida, are moderately 337 similar. The lack of highly homologous MSPs between different genera of Dorylaimia does not 338 allow discussing MSP phylogeny in this group and requires detailed phylogenetic study using 339 additional MSP samples from diverse taxa of this subclass. The fact that the similarity of MSP 340 sequences between representatives of three nematode subclasses is ranged from 48 to $75 \%$ show 341 that MSPs in Nematoda are less conserved proteins by sequences than it has been expected earlier. 342 MSP sequences retained high identity during approximate 500 million-year evolution withing 
343 order Rhabditida (Blaxter 2009) revealing protein sequence hyper-conservation (Kasimatis and

344 Phillips 2018). Nevertheless, MSP sequence hyper-conservation is not the case for phylum

345 Nematoda as a whole. This difference in MSPs variability between two major clades of nematodes

346 correlates well with sperm diversity which is very wide in Enoplea but relatively low in

347 Chormadorea, especially in the order Rhabditida where sperm patterns are enormously uniform

348 (Justine and Jamieson 1999; Slos et al. 2020; Yushin and Malakhov 2014).

349 In summary, we found the first evidences that E. brevis spermatozoa use MSP-based 350 locomotion and suggest that it may be the case for other species of Enoplia. Though, the early 351 evolution of nematodes is still unresolved due to controversy in different phylogenetic analyses 352 (Smythe et al. 2019), it is known that Enoplia is one of early-branching group, which reveals 353 presumably ancestral features among nematodes (Bik et al. 2010; Blaxter and Koutsovoulos 2015;

354 Felix 2004; Holterman et al. 2006; Joshi and Rothman 2005; Malakhov 1994, 1998; Rusin and 355 Malakhov 1998; Schulze and Schierenberg 2011; Smythe et al. 2019; van Megen et al. 2009; 356 Voronov 1999; Voronov and Panchin 1998; Yushin and Malakhov 2004). More basal phylogenetic 357 position of Enoplia in relation to Chromadorea should give a contribution to understanding of 358 origin and evolution of nematode sperm motility based of MSP function.

360 References

361 Afgan, E., Baker, D., Batut, B., van den Beek, M., Bouvier, D., Cech, M., et al. (2018). The Galaxy platform for accessible, reproducible and collaborative biomedical analyses: 2018 update. Nucleic Acids Research, 46(W1), W537-W544, doi:10.1093/nar/gky379.

364 Bik, H. M., Lambshead, P. J. D., Thomas, W. K., \& Lunt, D. H. (2010). Moving towards a complete molecular framework of the Nematoda: a focus on the Enoplida and earlybranching clades. BMC Evolutionary Biology, 10, 353, doi:10.1186/1471-2148-10-353.

367 Blaxter, M. (2009). Nematodes (Nematoda). In S. B. Hedges, \& S. Kumar (Eds.), The Timetree of Life (pp. 247-250). New York: Oxford University Press. 
Blaxter, M., \& Koutsovoulos, G. (2015). The evolution of parasitism in Nematoda. Parasitology, 142, S26-S39, doi:10.1017/s0031182014000791.

371

372

373

Bolger, A. M., Lohse, M., \& Usadel, B. (2014). Trimmomatic: a flexible trimmer for Illumina sequence data. Bioinformatics, 30(15), 2114-2120, doi:10.1093/bioinformatics/btu170.

Chu, D. S., \& Shakes, D. C. (2013). Spermatogenesis. Advances in Experimental Medicine and Biology, 757, 171-203, doi:10.1007/978-1-4614-4015-4_7.

De Ley, P., \& Blaxter, M. (2002). Systematic position and phylogeny. In D. L. Lee (Ed.), The Biology of Nematodes (pp. 1-30). London and New York: Taylor \& Francis.

del Castillo-Olivares, A., \& Smith, H. E. (2008). Critical contact residues that mediate polymerization of nematode major sperm protein. Journal of Cellular Biochemistry, 104(2), 477-487, doi:10.1002/jcb.21636.

Dereeper, A., Guignon, V., Blanc, G., Audic, S., Buffet, S., Chevenet, F., et al. (2008). Phylogeny.fr: robust phylogenetic analysis for the non-specialist. Nucleic Acids Research, 36(Web Server issue), W465-W469, doi:10.1093/nar/gkn180.

Do, C. B., Mahabhashyam, M. S., Brudno, M., \& Batzoglou, S. (2005). ProbCons: Probabilistic consistency-based multiple sequence alignment. Genome Research, 15(2), 330-340, doi:10.1101/gr.2821705.

Edgar, R. C. (2004). MUSCLE: multiple sequence alignment with high accuracy and high throughput. Nucleic Acids Research, 32(5), 1792-1797, doi:10.1093/nar/gkh340.

El-Gebali, S., Mistry, J., Bateman, A., Eddy, S. R., Luciani, A., Potter, S. C., et al. (2019). The Pfam protein families database in 2019. Nucleic Acids Research, 47(D1), D427-D432, doi:10.1093/nar/gky995.

Ellis, R. E., \& Stanfield, G. M. (2014). The regulation of spermatogenesis and sperm function in nematodes. Seminars in Cell \& Developmental Biology, 29, 17-30, doi:10.1016/j.semcdb.2014.04.005. 
394 Felix, M.-A. (2004). Developmental biology of nematodes-what we learn from Caenorhabditis

395

396

397

398

399

400

401

402

403

404

405

406

407

408

409

410

411

412

413

414

415

416

417 elegans. In Z. X. Chen, S. Y. Chen, \& D. W. Dickson (Eds.), Nematology-Advances and Perspectives (Vol. 1, pp. 71-174). Wallingford, UK: CABI Publishing.

Gasteiger, E., Hoogland, C., Gattiker, A., Wilkins, M. R., Appel, R. D., \& Bairoch, A. (2005). Protein identification and analysis tools on the ExPASy server. In J. M. Walker (Ed.), The Proteomics Protocols Handbook (pp. 571-607): Humana Press.

Heger, P., Kroiher, M., Ndifon, N., \& Schierenberg, E. (2010). Conservation of MAP kinase activity and MSP genes in parthenogenetic nematodes. BMC Developmental Biology, 10, 51, doi:10.1186/1471-213X-10-51.

Höglund, J., Engstrom, A., Morrison, D. A., Mineur, A., \& Mattsson, J. G. (2008). Limited sequence variation in the major sperm protein 1 (MSP) gene within populations and species of the genus Dictyocaulus (Nematoda). Parasitology Research, 103(1), 11-20, doi:10.1007/s00436-008-0877-8.

Hojas, R. M., \& Post, R. J. (2000). Regional genetic variation in the major sperm protein genes of Onchocerca volvulus and Mansonella ozzardi (Nematoda: Filarioidea). International Journal of Parasitology, 30(14), 1459-1465.

Holterman, M., van der Wurff, A., van den Elsen, S., van Megen, H., Bongers, T., Holovachov, O., et al. (2006). Phylum-wide analysis of SSU rDNA reveals deep phylogenetic relationships among nematodes and accelerated evolution toward crown Clades. Molecular Biology and Evolution, 23(9), 1792-1800, doi:10.1093/molbev/ms1044.

Joshi, P. M., \& Rothman, J. H. (2005). Nematode gastrulation: Having a BLASTocoel! Current Biology, 15(13), R495-R498, doi:10.1016/j.cub.2005.06.030.

Justine, J.-L. (2002). Male and female gametes and fertilisation. In D. L. Lee (Ed.), The Biology of Nematodes. (pp. 73-120). London and New York: Taylor \& Francis. 
418 Justine, J.-L., \& Jamieson, B. G. M. (1999). Nematoda. In B. G. M. Jamieson (Ed.),

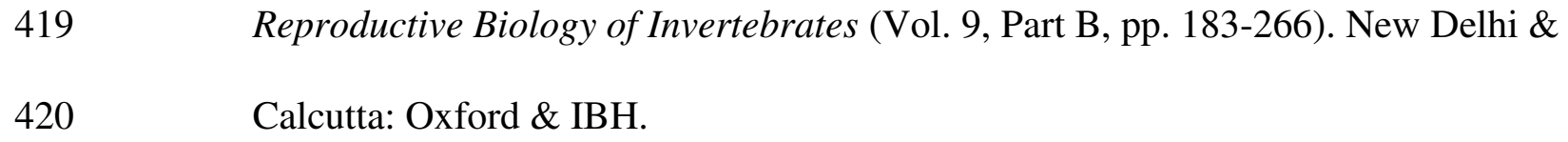

421 Kasimatis, K. R., \& Phillips, P. C. (2018). Rapid gene family evolution of a nematode sperm 422 protein despite sequence hyper-conservation. G3: Genes, Genomes, Genetics, 8(1), 353$423 \quad 362$, doi:10.1534/g3.117.300281.

424 King, K. L., Stewart, M., \& Roberts, T. M. (1994). Supramolecular assemblies of the Ascaris 425 suum major sperm protein (MSP) associated with amoeboid cell motility. Journal of Cell $426 \quad$ Science, 107 ( Pt 10), 2941-2949.

427 King, K. L., Stewart, M., Roberts, T. M., \& Seavy, M. (1992). Structure and macromolecular 428

430 Klass, M. R., \& Hirsh, D. (1981). Sperm isolation and biochemical analysis of the major sperm 431 432 protein from Caenorhabditis elegans. Developmental Biology, 84(2), 299-312, doi:10.1016/0012-1606(81)90398-5.

Lak, B., Yushin, V. V., Slos, D., Claeys, M., Decraemer, W., \& Bert, W. (2015). High-pressure freezing and freeze-substitution fixation reveal the ultrastructure of immature and mature spermatozoa of the plant-parasitic nematode Trichodorus similis (Nematoda;

Malakhov, V. V. (1994). Nematodes. Structure, development, classification and phylogeny. Triplonchida; Trichodoridae). Micron, 77, 25-31, doi:10.1016/j.micron.2015.05.012. Washington, USA: Smithsonian Institution Press.

Malakhov, V. V. (1998). Embryological and histological peculiarities of the order Enoplida, a primitive group of nematodes. Russian Journal of Nematology, 6(1), 41-46.

Marcello, M. R., Singaravelu, G., \& Singson, A. (2012). Fertilization. Advances in Experimental Medicine and Biology, 757, 321-350, doi:10.1007/978-1-4614-4015-4_11. 
443 Miyata, M., Robinson, R. C., Uyeda, T. Q. P., Fukumori, Y., Fukushima, S. I., Haruta, S., et al. 444 (2020). Tree of motility - A proposed history of motility systems in the tree of life. Genes 445 to Cells, 25(1), 6-21, doi:10.1111/gtc.12737.

446 Morrow, E. H. (2004). How the sperm lost its tail: the evolution of aflagellate sperm. Biological 447 Reviews of the Cambridge Philosophical Society, 79(4), 795-814, $448 \quad$ doi:10.1017/s1464793104006451.

449 Poinar, G. O., \& Hess-Poinar, R. T. (1993). The fine-structure of Gastromermis sp (Nematoda, 450 Mermithidae) sperm. Journal of Submicroscopic Cytology and Pathology, 25(3), 417$451 \quad 431$.

452 Roberts, T. M., \& Stewart, M. (2000). Acting like actin. The dynamics of the nematode major 453 sperm protein $(\mathrm{msp})$ cytoskeleton indicate a push-pull mechanism for amoeboid cell 454 motility. Journal of Cell Biology, 149(1), 7-12, doi:10.1083/jcb.149.1.7.

455 Roberts, T. M., \& Stewart, M. (2012). Role of major sperm protein (MSP) in the protrusion and 456 retraction of Ascaris sperm. International Review of Cell and Molecular Biology, 297, 457 265-293, doi:10.1016/b978-0-12-394308-8.00007-8.

458 Rusin, L. Y., \& Malakhov, V. V. (1998). Free-living marine nematodes possess no eutely. 459 Doklady Biological Sciences, 361, 331-333.

460 Ryan, G. L., Petroccia, H. M., Watanabe, N., \& Vavylonis, D. (2012). Excitable actin dynamics 461 in lamellipodial protrusion and retraction. Biophysical Journal, 102(7), 1493-1502, 462 doi:10.1016/j.bpj.2012.03.005.

463 Schmidt-Rhaesa, A. (1997/98). Phylogenetic relationships of the Nematomorpha - a discussion 464 of current hypotheses. Zoologischer Anzeiger, 236, 203-216.

465 Schulze, J., \& Schierenberg, E. (2011). Evolution of embryonic development in nematodes. 466 EvoDevo, 2(1), 18, doi:10.1186/2041-9139-2-18. 
467 Scott, A. L., Dinman, J., Sussman, D. J., \& Ward, S. (1989). Major sperm protein and actin

468

469

470

471

472

473

474

475

476

477

478

479

480

481

482

483

484

485

486

487

488

489

490

491

492 genes in free-living and parasitic nematodes. Parasitology, 98 Pt 3, 471-478, doi:10.1017/s0031182000061564.

Sepsenwol, S., Ris, H., \& Roberts, T. M. (1989). A unique cytoskeleton associated with crawling in the amoeboid sperm of the nematode, Ascaris suum. Journal of Cell Biology, 108(1), 55-66, doi:10.1083/jcb.108.1.55

Shepherd, A. M. (1981). Interpretation of sperm development in nematodes. Nematologica, 27(1), 122, doi:10.1163/187529281X00151.

Singaravelu, G., \& Singson, A. (2011). New insights into the mechanism of fertilization in nematodes. International Review of Cell and Molecular Biology, 289, 211-238, doi:10.1016/b978-0-12-386039-2.00006-7.

Slos, D., Yushin, V. V., Claeys, M., Ivanova, E. S., Kosaka, H., \& Bert, W. (2020). Structure, development, and evolutive patterns of spermatozoa in rhabditid nematodes (Nematoda: Rhabditida). Journal of Morphology, 281(11), 1411-1435, doi:10.1002/jmor.21255.

Smith, H. E. (2014). Nematode sperm motility. WormBook, 1-15, doi:10.1895/wormbook.1.68.2.

Smythe, A. B., Holovachov, O., \& Kocot, K. M. (2019). Improved phylogenomic sampling of free-living nematodes enhances resolution of higher-level nematode phylogeny. BMC Evolutionary Biology, 19(1), 121, doi:10.1186/s12862-019-1444-x.

Strube, C., Buschbaum, S., \& Schnieder, T. (2009). Molecular characterization and real-time PCR transcriptional analysis of Dictyocaulus viviparus major sperm proteins. Parasitology Research, 104(3), 543-551, doi:10.1007/s00436-008-1228-5.

Tarr, D. E. K., \& Scott, A. L. (2005). MSP domain proteins. Trends in Parasitology, 21(5), 224231, doi:10.1016/j.pt.2005.03.009.

van Megen, H., van den Elsen, S., Holterman, M., Karssen, G., Mooyman, P., Bongers, T., et al. (2009). A phylogenetic tree of nematodes based on about 1200 full-length small subunit ribosomal DNA sequences. Nematology, 11, 927-S927, doi:10.1163/156854109x456862. 
493 Voronov, D. A. (1999). The embryonic development of Pontonema vulgare (Enoplida :

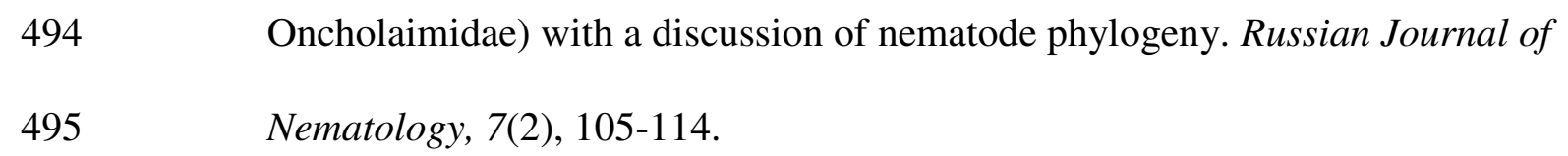

496 Voronov, D. A., \& Panchin, Y. V. (1998). Cell lineage in marine nematode Enoplus brevis.

497 Development, 125(1), 143-150.

498 Waterhouse, A. M., Procter, J. B., Martin, D. M., Clamp, M., \& Barton, G. J. (2009). Jalview

499 Version 2--a multiple sequence alignment editor and analysis workbench. Bioinformatics, 500 25(9), 1189-1191, doi:10.1093/bioinformatics/btp033.

501 Yushin, V. V., Afanasiev-Grigoriev, A. G., \& Malakhov, V. V. (2014). The male gonad of the 502 marine nematode Enoplus: no single distal tip cell but multiple uniform epithelial cells. 503 Invertebrate Zoology, 11(2), 361-372, doi:10.15298/invertzool.11.2.07.

504 Yushin, V. V., Claeys, M., \& Bert, W. (2016). Ultrastructural immunogold localization of major 505 sperm protein (MSP) in spermatogenic cells of the nematode Acrobeles complexus 506 (Nematoda, Rhabditida). [Article]. Micron, 89, 43-55, doi:10.1016/j.micron.2016.07.004. 507 Yushin, V. V., \& Malakhov, V. V. (1994). Ultrastructure of sperm cells in the female gonoduct 508 of free-living marine nematodes from genus Enoplus (Nematoda: Enoplida).

$509 \quad$ Fundamental and Applied Nematology, 17(6), 513-520.

510 Yushin, V. V., \& Malakhov, V. V. (2004). Spermatogenesis and nematode phylogeny. In R. C. 511 Cook, \& D. J. Hunt (Eds.), Proceeding of the Fourth International Congress of Nematology (Vol. 2, pp. 655-665, Nematology Monographs and Perspectives).

Yushin, V. V., \& Malakhov, V. V. (2014). The origin of nematode sperm: Progenesis at the cellular level. Russian Journal of Marine Biology, 40(2), 71-81, doi:10.1134/S1063074014020114.

Zograf, J. K. (2014). Ultrastructure of spermatogenesis and sperm of the free-living soil nematode Panagrellus redivivus (Rhabditida: Panagrolaimidae). Russian Journal of Nematology, 22(1), 39-48. 


\section{$520 \quad$ Figure legends}

521 Fig. 1 Phylogeny of nematodes and MSP-based sperm motility. Phylogenetic relationships within phylum Nematoda derived primarily from SSU rDNA sequence data are given according to De

523 Ley and Blaxter (De Ley and Blaxter 2002). Suborders of Rhabditida order, in which

524 representatives highly homologous MSPs are found at DNA, RNA or protein levels, are marked

525 by underlining. Taxa whose species used in this study are marked with asterisks. Orders Trefusiida,

526 Isolaimida, Dioctophymatida, Muspiceida, Marimermithida and Desmoscolecida are not shown in 527 this tree.

Fig. 2 Western blot analysis of MSP in P. redivivus. In adult animals, MSP is detected as double

530 band with approximate weight 15 and $16 \mathrm{kDa}$. Both male and female samples reveal MSP signal,

531 because the latter include mated females. $\alpha$-Tubulin was used as a loading control (approximate weight $55 \mathrm{kDa})$.

534 Fig. 3 Immunolocalization of MSP in P. redivivus sperm. a Immature spermatozoa extracted from

535 male. MSP localizes in granules. In some cells, MSP has strongest signals in the periphery 536 (arrowheads) (scale bar $10 \mu \mathrm{m}$ ). b Chain of activated spermatozoa extracted from female. MSP 537 has punctate and fibrillar pattern of distribution in pseudopodia that marked by arrows. Selected 538 area is given in higher magnification (scale bar $10 \mu \mathrm{m}$, magnified area $2 \mu \mathrm{m}$ ).

540 Fig. 4 Western blot analysis of MSP in E. brevis. a MSP has unusual mobility in gel and is found 541 as protein with weight $36-38 \mathrm{kDa}$. Both male and female samples reveal MSP signal, because the 542 latter include inseminated females. $\alpha$-Tubulin was used as a loading control (approximate weight $54355 \mathrm{kDa}$ ). b Peptide competition assay confirms reactivity of anti-MSP antibodies with protein band 544 of $36-38 \mathrm{kDa}$. 
546 Fig. 5 Immunolocalization of MSP in E. brevis sperm. a Immature spermatozoon from male. MSP

547 concentrates in large granules (scale bar $10 \mu \mathrm{m}$ ). b Spermatozoon recovered from male and 548 partially activated by 10 min incubation in sea water. MSP revealed more diffuse pattern with 549 appearance of longitudinal fibrillar structures. Selected area is given in higher magnification (scale 550 bar $10 \mu \mathrm{m}$, magnified area $2 \mu \mathrm{m}$ ). c Mature spermatozoon from female. Most of MSP signal is 551 found in pseudopod (scale bar $10 \mu \mathrm{m}$ ).

552

553 Fig. 6 Putative MSPs that are most similar to peptide antigen. a $P$. redivivus MSPs aligned with peptide antigen. Protein sequences (Pan_g61.t1, Pan_g6018.t1, Pan_g6424.t1, Pan_g9068.t1, Pan_g19433.t1 and Pan_g21178.t1) were found by Blast using peptide antigen as query in

556 WormBase Parasite (https://parasite.wormbase.org). b E. brevis MSPs aligned with peptide 557 antigen. Multiple alignment was performed using ProbCons and visualized in Jalview with BLOSUM62 color scheme.

560 Fig. 7 Multiple alignment and phylogenetic relationships of MSPs. a Multiple alignment of MSPs 561 from 13 taxa of three subclasses of Nematoda. MSPs of six Rhabditida, four Dorylaimia and one 562 Enoplia species were used. Multiple alignment was performed using ProbCons and visualized in 563 Jalview with BLOSUM62 color scheme. MSP sequences of nematodes and MSP domains of 564 Sacharomyces cerevisiae and Homo sapiens used in multiple alignment were downloaded from 565 following databases, GenBank (https://www.ncbi.nlm.nih.gov) (A. suum: CAA63933.1, 566 Dictyocaulus viviparus: AAB27962.2, Strongyloides ratti: XP_024503659.1, Trichuris trichiura:

567 CDW57515.1, Trichinella nativa: OUC40810.1, Trichinella pseudospiralis: KRX99722.1, 568 Trichinella papuae: KRZ74366.1, S. cerevisiae MSP domain of Scs22p: AJP97989.1), WormBase 569 Parasite (https://parasite.wormbase.org) ( $P$. redivivus: Pan_g9068.t1) and UniProt 570 (https://www.uniprot.org) (C. elegans: P53017, Onchocerca volvulus: P13262.3, H. sapiens MSP 
571 domain of VAPA: Q9P0L0). b Maximum likelihood tree with SH-aLRT branch support. Only 572 significant values $(\geq 0.8)$ are shown. MSP domains of $S$. cerevisiae (Scs22p) and H. sapiens 573 (VAPA) proteins were chosen as an outgroup.

574

575 


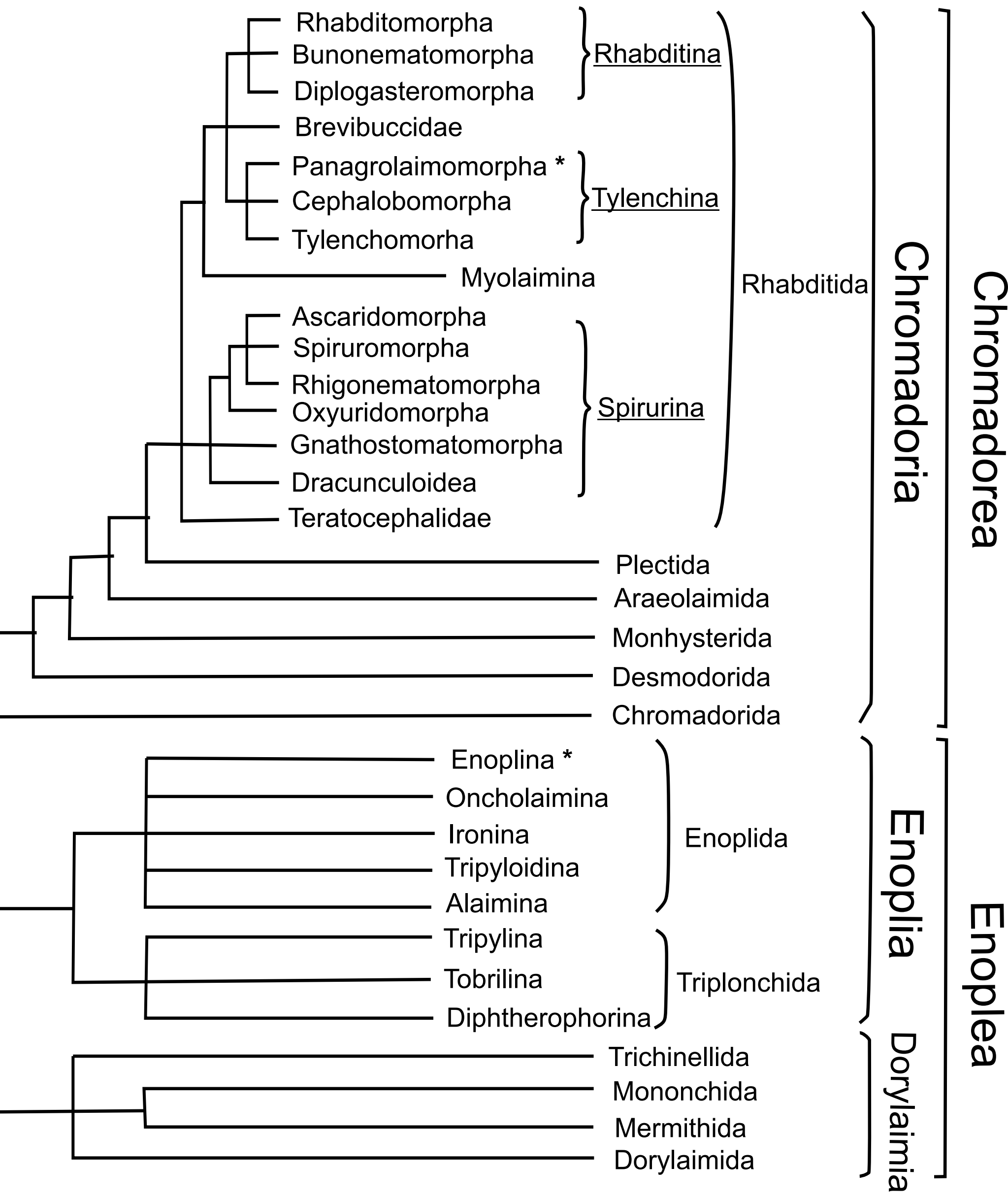


m f

22 kDa -

14 kDa -

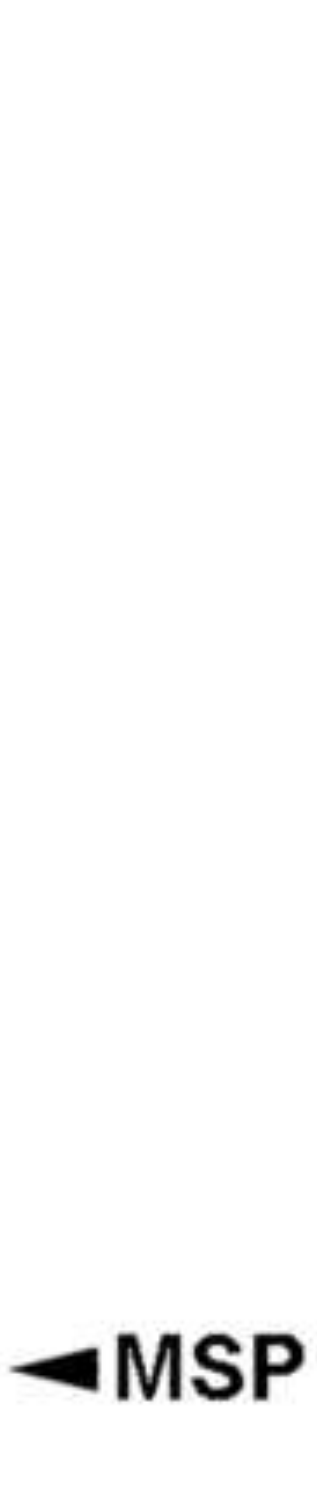

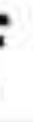

$\mathrm{Da}-$
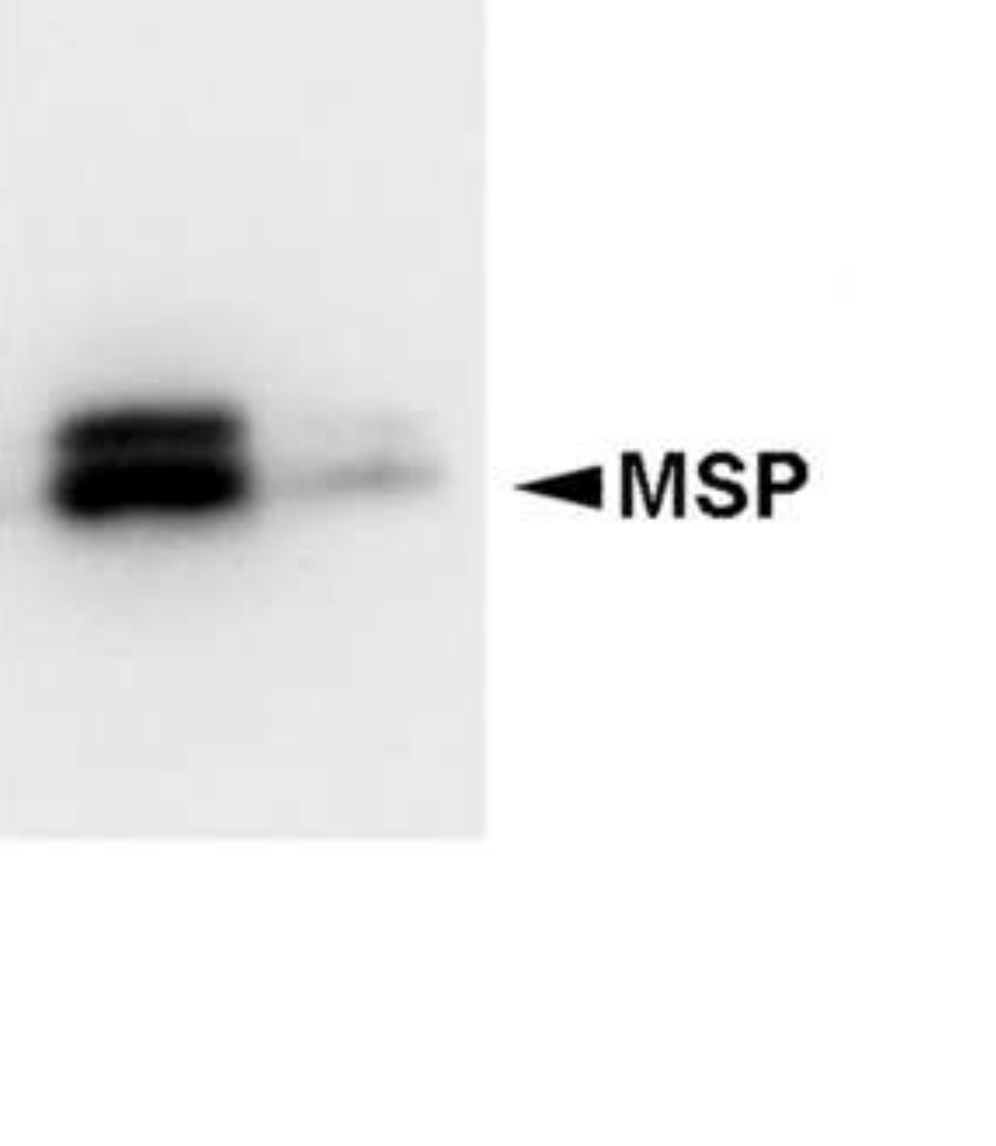

\section{m f

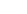

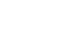

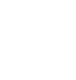

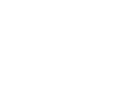

.

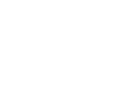

. 


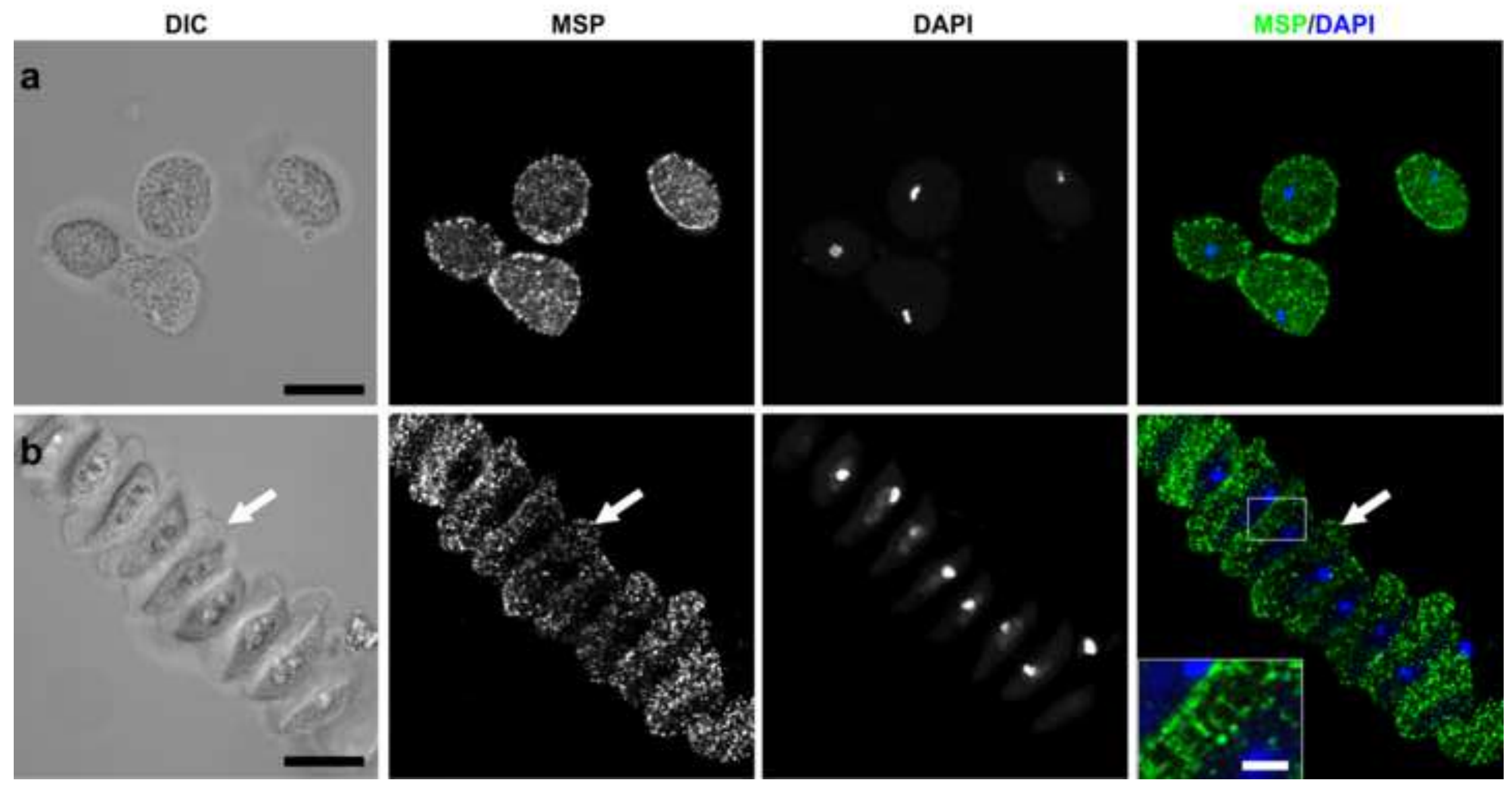


a
m f

b

\section{a-tubulin}

peptide

m f

$42 \mathrm{kDa}-$

$$
\text { MSP }
$$

$42 \mathrm{kDa}$ MSP -

$29 \mathrm{kDa}$ -

29 kDa - 


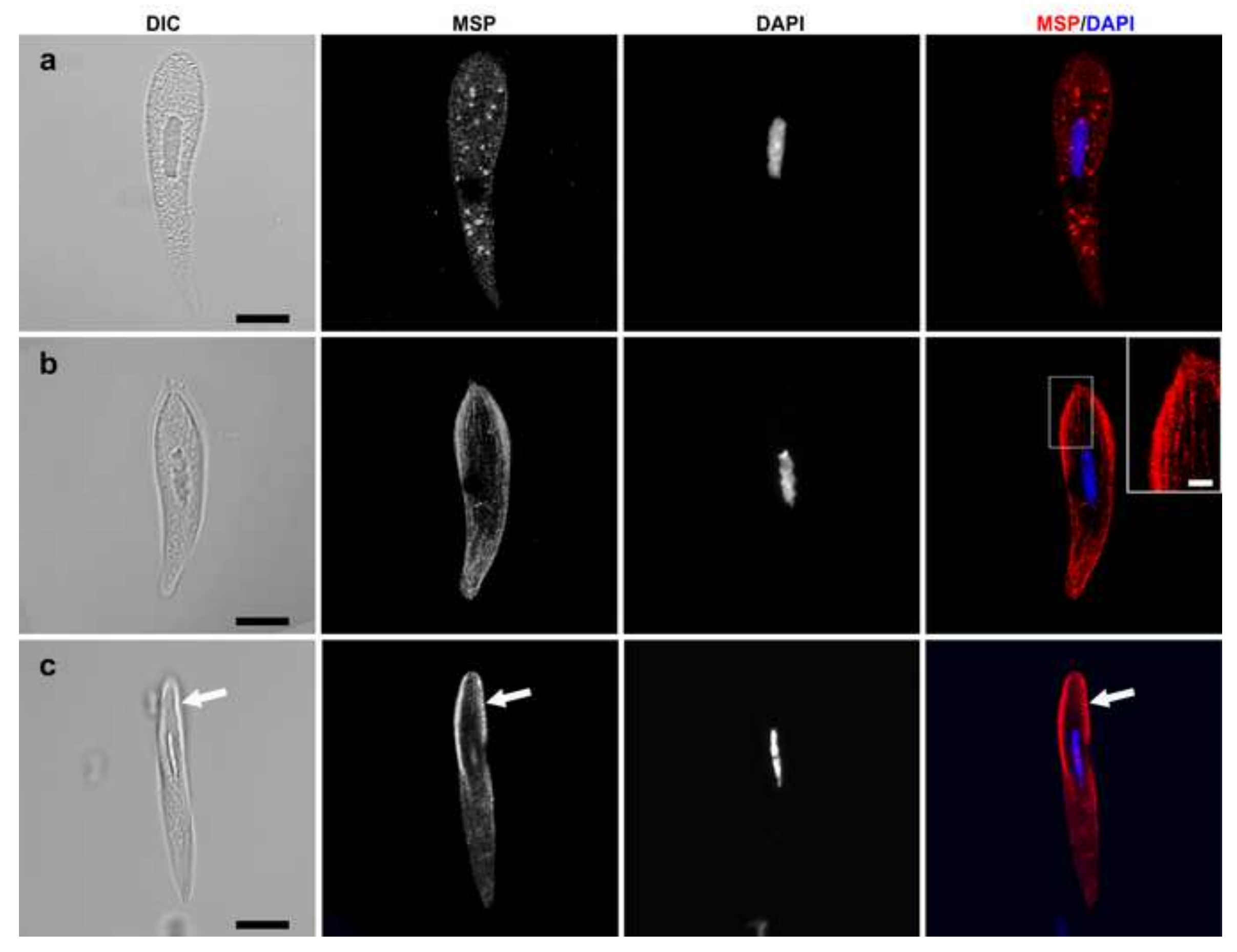




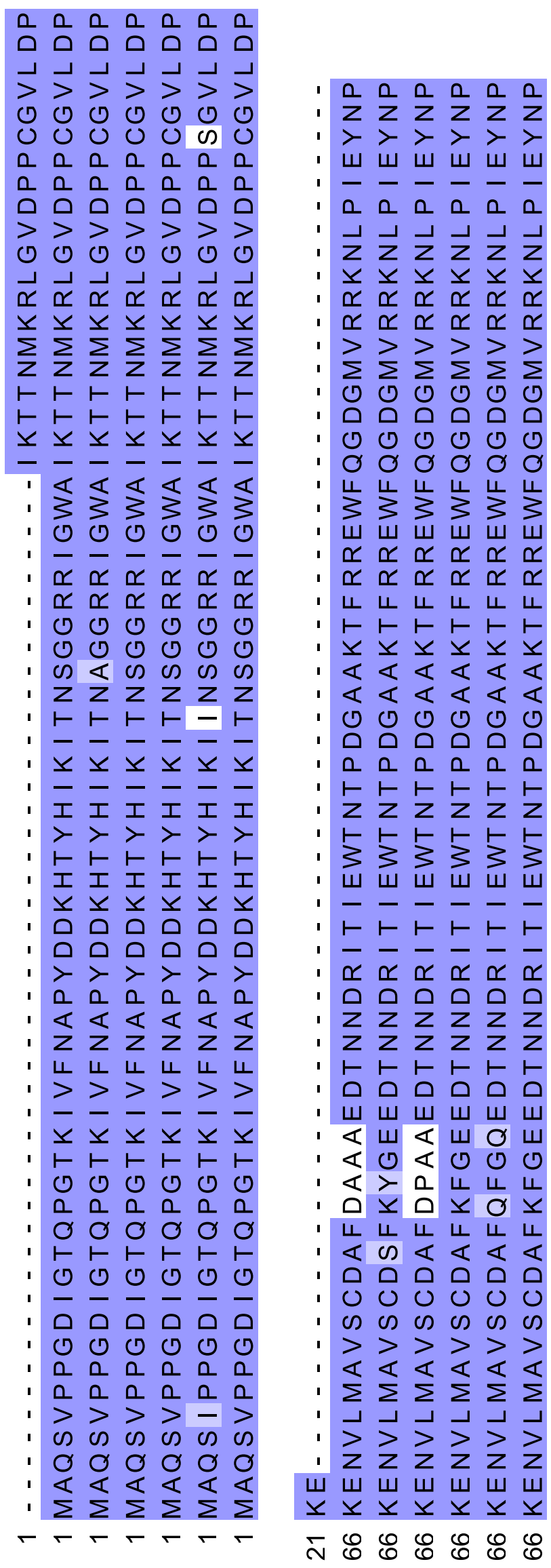

ฮิ $\mp \mp \mp \mp$

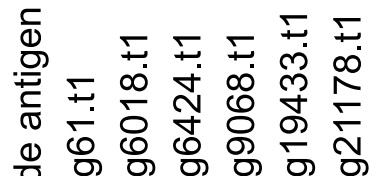
స ๘ ธ

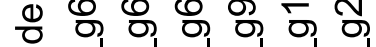

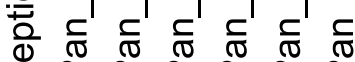

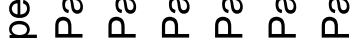

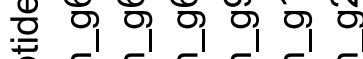

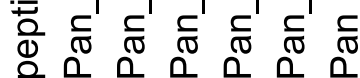

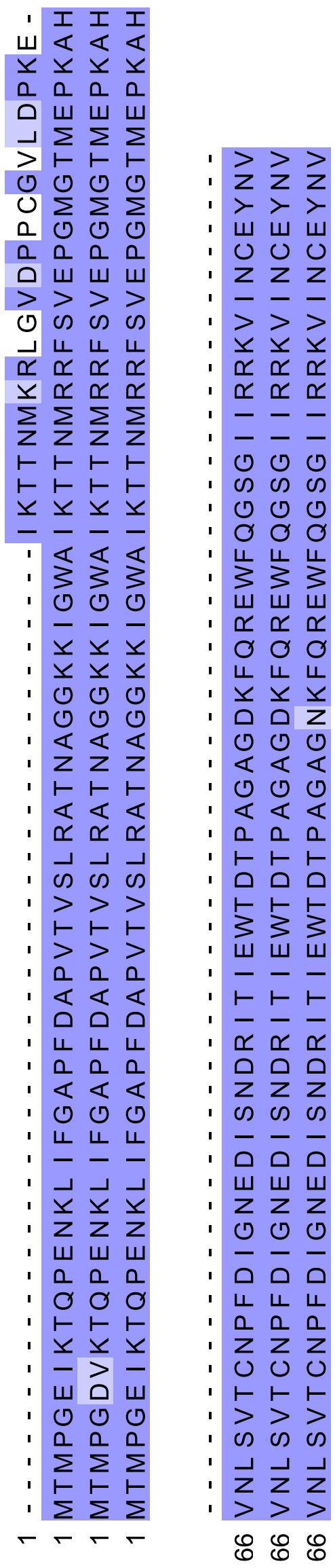

山 $\varangle<$

$x \geq x \underline{\square}$

ே ш ш

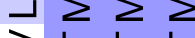

Uण 00

உш ш

U) の

\ய レ

Z Z Z

$-\vdash \vdash \vdash$

$x \leq x \leq$

$1 \ll \ll<$

000

$x x y$

$x \leq x$

(1) 0

(1) 0

$\leftarrow<\varangle$

$\ll<\ll$

$\propto \propto \propto$

$\vec{\omega} \omega$

$>>>$

$1-1$

20

$<<<$

○

$\varangle<\varangle$

000

レ レ レ

$\neg-$

Шய

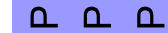

o 00

$\vdash \vdash \vdash$

$x \leq x$

ш

(1) 10

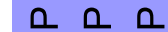

$\sum \Sigma \sum$

上

$\leftarrow \leftarrow \sigma$

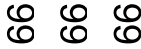

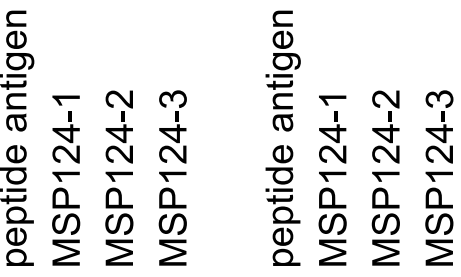


S. cerevisiae MSP domain of Scs22p H. sapiens MSP domain of VAPA

T. pseudospiralis

T. papuae

T. nativa

T. trichiura

E. brevis MSP124-1

E. brevis MSP124-2

E. brevis MSP124-3

C. elegans

D. viviparus

$P$. redivivus

S. ratti

O. volvulus

A. suum

S. cerevisiae MSP domain of Scs22p $H$. sapiens MSP domain of VAPA

T. pseudospiralis

T. papuae

T. nativa

T. trichiura

E. brevis MSP124-1

E. brevis MSP124-2

E. brevis MSP124-3

C. elegans

$D$. viviparus

P. redivivus

S. ratti

O. volvulus

A. suum

S. cerevisiae MSP domain of Scs22p $H$. sapiens MSP domain of VAPA

T. pseudospiralis

T. papuae

T. nativa

T. trichiura

E. brevis MSP124-1

E. brevis MSP124-2

E. brevis MSP124-3

C. elegans

D. viviparus

P. redivivus

S. ratti

O. volvulus

A. suum
1 MR - . . . . . I IVP - EKLLFKAPL NKQSTEYI KLENDGEKRVIFKVRTS 1 IL - . - . - - VLDPPTDLKFKGPFTDVVTT NL KL RNPSDRKVCFKVKTT 1 MRNE - I PHD I | I EPSTCLFFNGPFDEAKSQSVRMRNPGGQAVAWA I KTN 1 MRNE - I PHD I T I EPSTCLFFNGPFDETKSQAVRMRNPGGQA I AWA I KTN 1 MPKP - I PSELKTSPAER I VFNAPFEEKKNYPFS I INNGKEK I AYM I KL S 1 MAKQ - MPAD I KTEPLDKLYFNAPFKEKKNYK I AVTNTGAKPL AWCVKST $1 \mathrm{MT}$ - - - MPGE I KTQPENKL I FGAPFDAP VTVSLRAT NAGGKK I GWA I KT T $1 \mathrm{MT}$ - - - MPGDVKTQPENKL I FGAPFDAPVTVSLRATNAGGKK I GWA I KTT $1 \mathrm{MT}$ - - - MPGE I KTQPENKL I FGAPFDAPVTVSLRATNAGGKK I GWA I KTT 1 MAQSVPPGD IQTQPGTK I VFNAPYDDKHTYHIKVINSSARR I GYG IKTT 1 MAS - VPPGD I NTQPNSK I VFNAPYDDKHTYHI K I I NASGRR I GWA I KT T 1 MAQSVPPGD I GTQPGTK I VFNAPYDDKHTYHIKI TNSGGRR I GWA I KT T 1 MAQS VPPGD I QTQPGTK I VFNAPYDDKHTYHI K I TNSGGRR I GWA I KT T 1 MAQSVPPGD I HTQPGSK I VFNAPYDDKHTYHIN I TNAGGRR I GWA I KT T 1 MAQS VPPGD I NTQPSQK I VFNAPYDDKHTYHIKITNAGGRR I GWA IKT T

40 APTKYCVRPNVA I I GAHESVNVQ I VFLGLPKSTADDEMDQKRDKFL I VT 42 APRRYCVRPNSG I I DPGSTVTVSVMLQPFDYDPN - - - EKSKHKFMVQT 49 NRARL NAEPPGG I LQAGTQ I AVN I I SAPVRRAHQVG - - KQESDS I I FEW 49 NRARL NAEPPGG I LQAGTQ I VVN I I SAPVRRAHQVG - - KQENDS I I FEW 95 49 NEMRTMCEPSHGVLNPGEN I WI RVHLEEFKPTVE _ . . NTQPNTLTIEY 93 49 NVSR I SFDPSAGVLDANETFMFTAVTEVFEPTPE - . - NLKQDQ I T I EW 93 47 NMRRF SVEPGMG TMEPKAHVNL SVT CNPFD I GNE - . - - D I SNDR I T I EW 91 47 NMRRF SVEPGMGTMEPKAHVNL SVT CNPFDIGNE _ . - - D I SNDR I T I EW 91 47 NMRRFS VEPGMGTMEPKAHVNL SVTCNPFDIGNE - . - DISNDR I T I EW 91 50 NMKRLGVDPPCGVLDPKEAVLLAVSCDAFAFGQE - . . - DTNNDRITVEW 94 49 NMKRLGVDPACGVLDPKEATLMAVSCDTFEYGRE - . - DTNNDRITVEW 93 50 NMKRLGVDPPCGVLDPKENVLMAVSCDAFKFGEE - - - DTNNDR I T I EW 94 50 NMKRLGVDPPSGVLDPKENVLMAVSCDAFAYGQE - . - DTNNDR I T I EW 94 50 NMKRLGVDPPCGVLDPKENVLMAVSCDTFDATRE - . - D I NNDR I T IEW 94 50 NMRRL SVDPPCGVLDPKEKVLMAVSCDTFNAATE - - - DLNNDR I T I EW 94

89 LP I PAAYQNV . . . . . . . . . EDGELLSDW

87 I FAPPNTSDM - . - . . - . EAVWKEAKP 96 CQVES - - DI PFS I ELLKGDALLRRRK I K I I YNP 96 CQVES - - D I PFS I DLLKGDALLRRRK I K I I YNP 94 CFPPEGSDKNFNPSWFRLNV I I RRKHVALEFNA 94 I LAPDGEGRKF NREWMQRDV I VRRKH I TVFYNP 92 TDTPAGAGDKFQREWFQGSG I I RRKV I NCEYNV 92 TDTPAGAGDKFQREWFQGSG I I RRKV I NCEYNV 92 TDTPAGAGNKFQREWFQGSG I I RRKV I NCEYNV 95 TNTPDGAAKQFRREWFQGDGMVRRKNLP I EYNP 94 CNTPDGAAKQFRREWFQGDGMVRRKNLP I EYNP 95 TNTPDGAAKTFRREWFQGDGMVRRKNLP I EYNP 95 TNTPDGAAKTFRREWFQGDGMVRRKNLP I EYNP 95 TNTPDGAAKQFRREWFQGDGMVRRKNLP I EYNL 95 TNTPDGAAKQFRREWFQGDGMVRRKNLPI EYNL

48 48 48 48 46 46 46 49 48 49 49 49 49

88 86 95 95 .

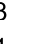
,

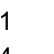

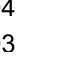

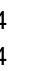

4
.

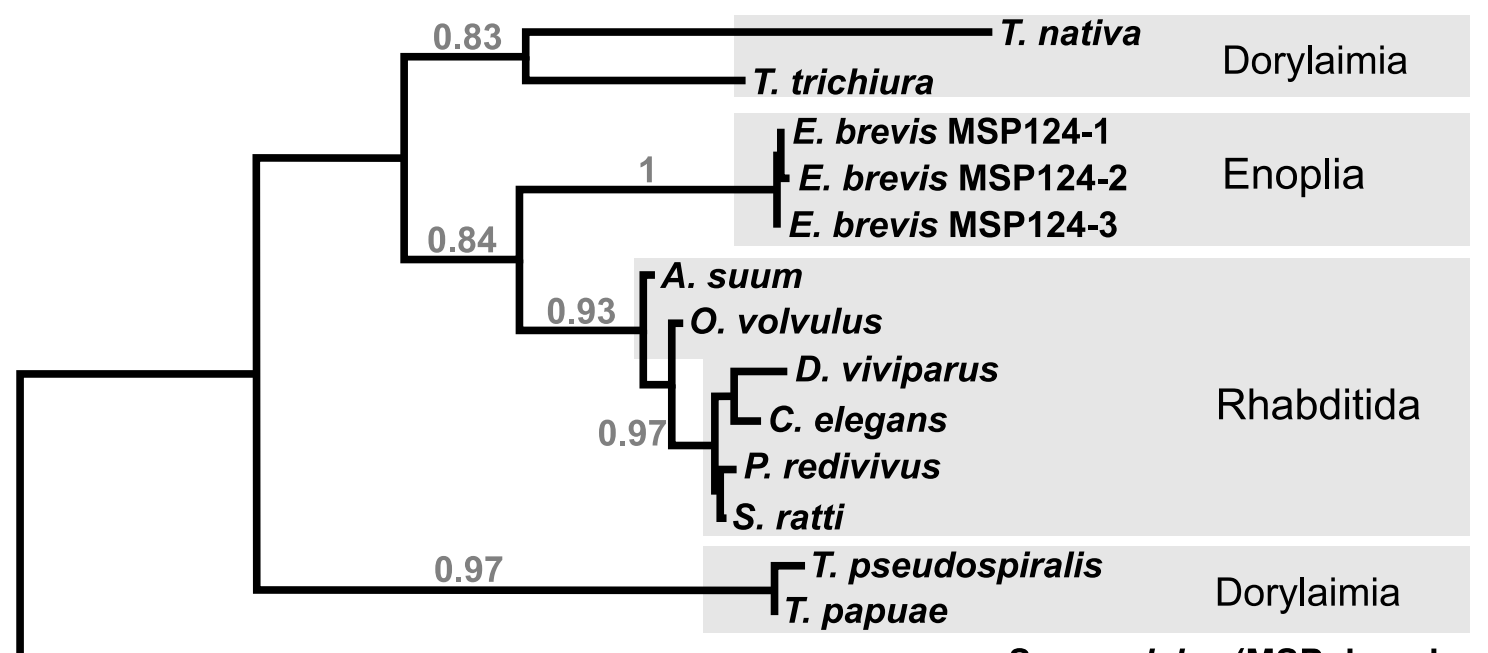




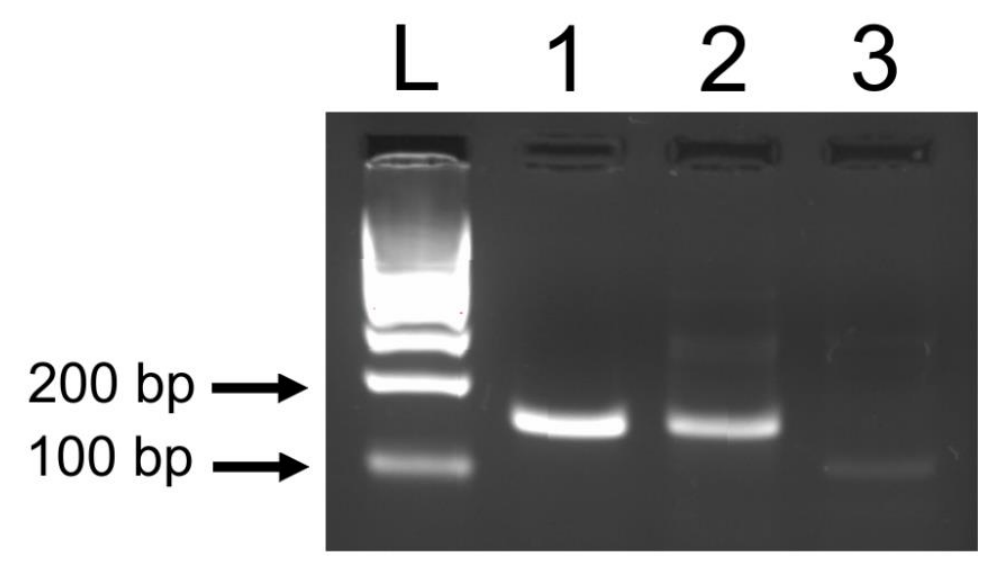

FIGURE S2 RT-PCR analysis of the presence of putative MSP-coding transcripts found in $E$. brevis transcriptome. Fragments corresponding to MSP mRNAs were amplified and then resolved in 3\% SB gel, MSP124-1 (line 1, 162 bp), MSP124-2 (line 2, 166 bp) and MSP124-3 (line 3, 118 bp). Ladder is marked by $\mathrm{L}$. 
TABLE S1 Primers and conditions of amplification of MSP124 fragments by RT-PCR

\begin{tabular}{|c|l|c|c|c|}
\hline \multicolumn{1}{|c|}{ Pranscript } & \multicolumn{1}{|c|}{ Primer } & Ta & cycles & size, bp \\
\hline Msp124-1 & F: AACTTGTCCGTCACCTGCAAC & 58 & 25 & 162 \\
& R: GCAGTTGATCACCTTCCGG & & & \\
\hline Msp124-2 & F: AACTTGTCCGTCACCTGCAAC & 55 & 35 & 166 \\
& R: ATTCGCAGTTGATGACTTTCCTC & & & \\
\hline Msp124-3 & F: AACTTGTCCGTCACCTGCAAC & 55 & 35 & 118 \\
& R: ATTCCCGCTGGAACTTGTTG & & & \\
\hline
\end{tabular}

Note: to amplify fragments of all fragments the same forward primer was used. 


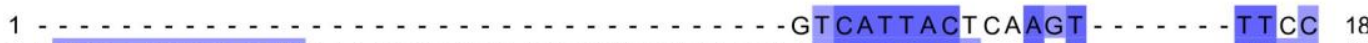
1 ACAAAATCCACT TCAAAGGCAGCACGCGAGTAAATAATCATTACC - - ACT - . - . TT T

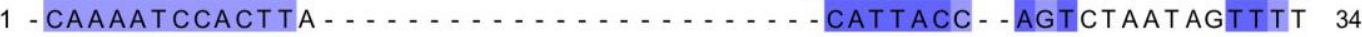

MSP124-1 MSP124-2 MSP124-3

19 AATCACCCAACCAGTGTTGTATTTCCTCTTCGAGCTGC - . - . - . - AAAATCTGCCATC 69 53 TCTCGCTTACAAAAGGTCGGTTTTTTTTGCTATCTCGTCAAACAACTAGAAACCCGCCATC 113 35 TTTAGTTTAGTTGCGGCTGTAATTTTTTTTCATAATCCAATTCTCCTGAAAATTCGTCAAG 95

MSP124-1

MSP124-2

MSP124-3

70 ATGACTATGCCAGGAGAAAT CAAGACCCAGCCGGAGAACAAGCTCATCT TCGGAGCTCCCT 130 114 ATGACT ATGCCCGGAGATGT CAAGACCCAGCCGGAGAACAAACTGATCT T CGGAGCCCCCT 174 96 ATGACTATGCCAGGCGAAAT CAAGACTCAGCCGGAAAACAAGCTCATCT TCGGGGCACCCT 156

MSP124-1

MSP124-2

MSP124-3

131 T CGATGCCCCTGTGACAGTCTCGCT CCGAGCTACCAACGCTGGAGGCAAGAAGATCGGCTG 191 175 T CGACGCT CCCGT GACGGT CT CCCT CAGAGCAACCAACG CT GGGGGCAAGAAGAT CGGCTG 235 157 T CGACGCT CCAGTCACAGTCT CGCT CCGTGCCACCAACGCTGGAGGAAAGAAGATTGGGTG 217

MSP124-1 MSP124-2 MSP124-3

192 GGCCAT CAAGACCACCAACATGCGCCGGTTT T CCGTGGAG CCGGGGATGGGGACCATGGAG 252 236 GGCCAT CAAGA C CA C CAACA T G CG CCGGT T T T CCG T GGAG CCGGGGATGGGGA C CA T GGAG 296 218 GGCCATAAAGACCACGAATATGCGCCGTT TCT CTGTGGAGCCGGGGATGGGCACCATGGAG 278

MSP124-1 MSP124-2 MSP124-3

253 CCCAAGGCCCACGTCAACCTGTCAGTCACCTGCAACCCGTTCGACATCGGCAACGAGGACA 313

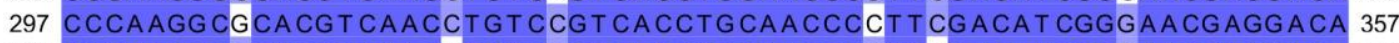
279 CCCAAGGCCCACG T CAACTTGTCCGT CACCTGCAACCCGTT T GACAT CGGGAACGAGGACA 339

MSP124-1

MSP124-2

MSP124-3

314 TCTCCAACGACCGGAT CACGAT CGAGTGGACGGACACGCCCGCCGGAGCCGGAGACAAGT T 374 358 T CT CCAACGACAGGAT CACGAT CGAGTGGACGGACACT C CGG CCGG CGCCGGAGACAAAT T 418 340 TCT CCAACGAT CGGATTACGAT CGAGTGGACCGACACCCCGGCCGGCGCCGGCAACAAGT T 400

MSP124-1 MSP124-2 MSP124-3

375 CCAGCGAGAATGGT T CCAGGGCT CCGGGAT CA T CCGCCGGAAGGTGAT CAACT G CGAG A A 435 419 C CAG CGCGAAT GGT T C CAGGGCT CTGGAAT CAT CAGGAGGAAGGT GAT CAACT G CGAG TAC 479 401 CCAG CGGGAAT GGT T CCAGGGCT CCGGGAT TAT CCGACGCAAGGTCAT CAACT G CGAGTAC 461

MSP124-1 MSP124-2 MSP124-3

MSP124-1 MSP124-2 MSP124-3

436 AACGTCTAGgCGgAGAAT T CGGAGgTG T CGgGAGTGAAGAGATT TGATCT T TGATT T TAAA 496 480 AACG T CT AGG CGGAGAAT T CGGAGGTGT CGGGAGTGAAGAGAT T TGATCT T TGAT T T TAAA 540 462 AACGTCTAG - - . - A AAGT CGCAG - - GCTGATAGGGATGATAT - . . . . - . ACT TGGAA 504 541 ATTTTACTTGGAGTATATGTAGTGACTTGTTTTTTAAGTTTTG

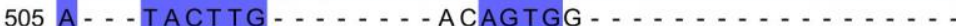

FIGURE S1 A group of E. brevis MSP transcripts called MSP124 that encode putative MSPs. Multiple alignment was done using MUSCLE and visualized in Jalview with Percentage Identity color scheme. Coding regions of the transcripts are underlined. 


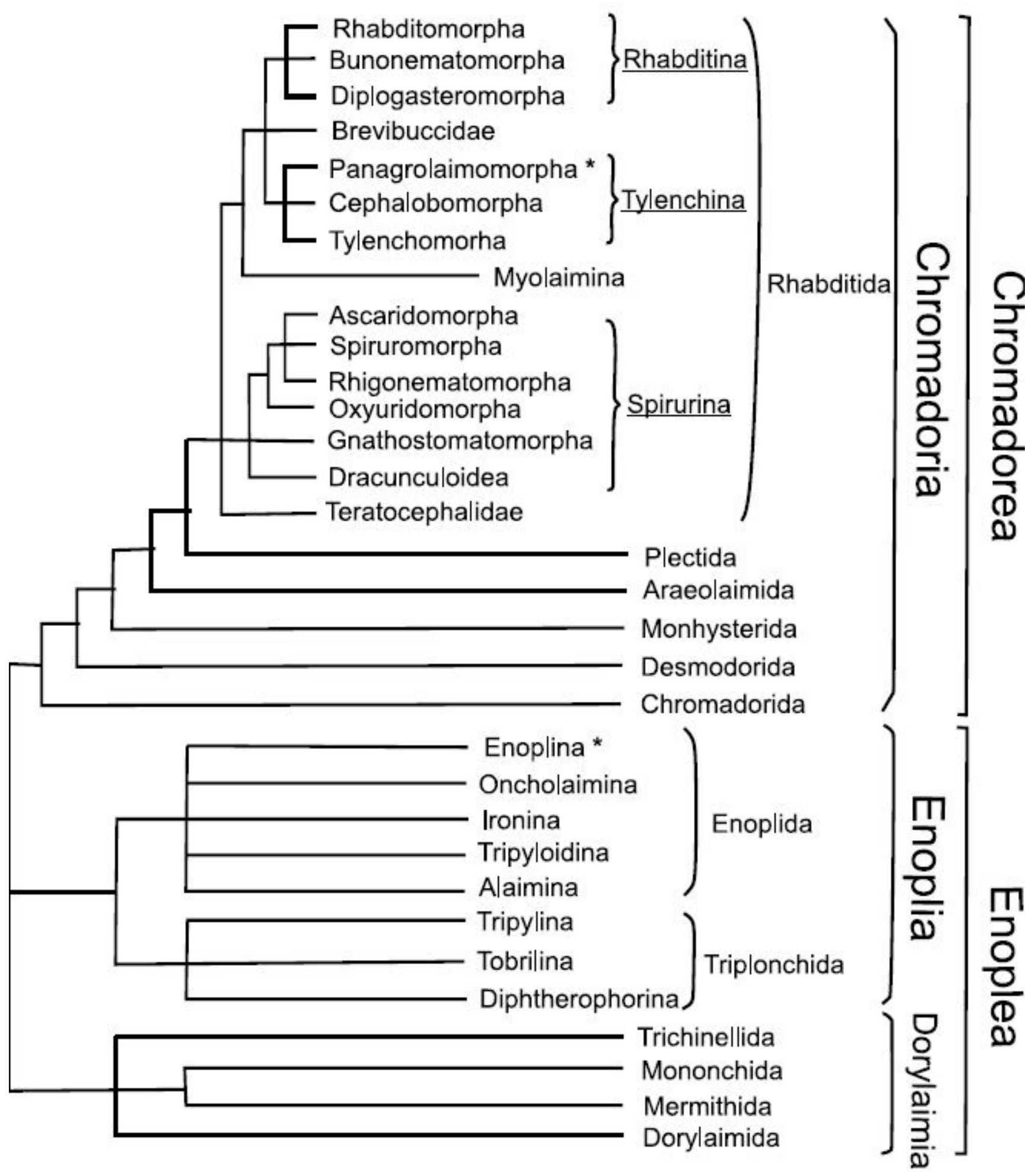

Figure 1

Phylogeny of nematodes and MSP-based sperm motility. Phylogenetic relationships within phylum Nematoda derived primarily from SSU rDNA sequence data are given according to De Ley and Blaxter (De Ley and Blaxter 2002). Suborders of Rhabditida order, in which representatives highly homologous MSPs 
are found at DNA, RNA or protein levels, are marked by underlining. Taxa whose species used in this study are marked with asterisks. Orders Trefusiida, Isolaimida, Dioctophymatida, Muspiceida, Marimermithida and Desmoscolecida are not shown in this tree.

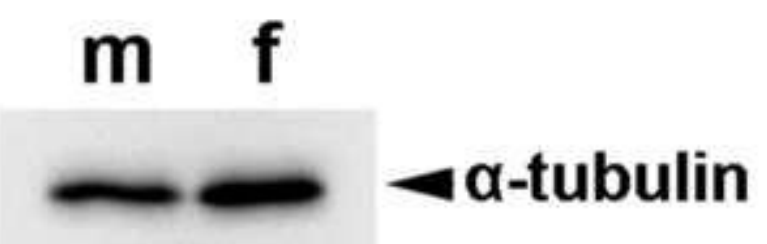

m f

\section{$22 \mathrm{kDa}-$}

\section{$14 \mathrm{kDa}=$}

\section{$\checkmark$ MSP}

\section{Figure 2}

Western blot analysis of MSP in P. redivivus. In adult animals, MSP is detected as double band with approximate weight 15 and $16 \mathrm{kDa}$. Both male and female samples reveal MSP signal, because the latter include mated females. a-Tubulin was used as a loading control (approximate weight $55 \mathrm{kDa}$ ). 
DIC

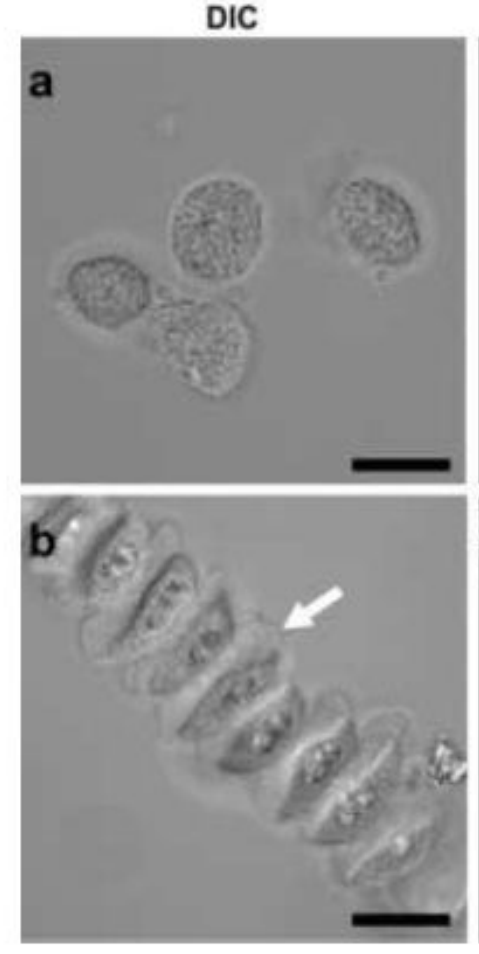

MSP
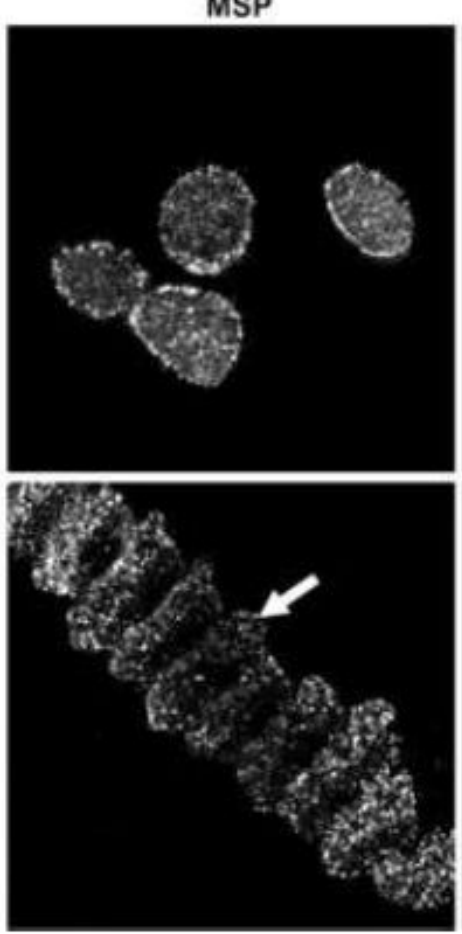

DAPI
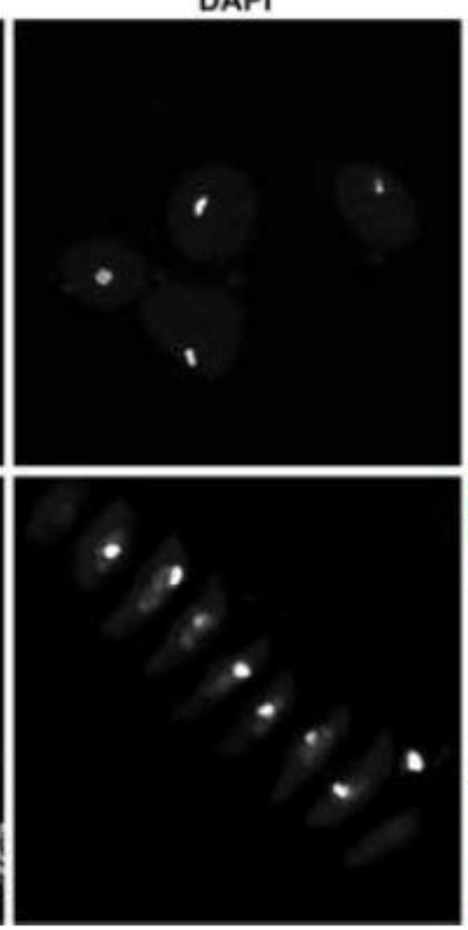

MSP/DAPI
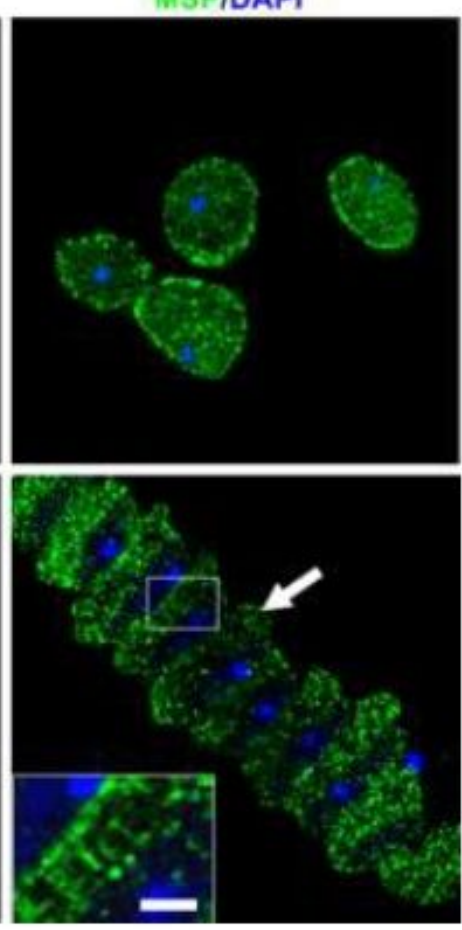

\section{Figure 3}

Immunolocalization of MSP in P. redivivus sperm. a Immature spermatozoa extracted from male. MSP localizes in granules. In some cells, MSP has strongest signals in the periphery (arrowheads) (scale bar $10 \mu \mathrm{m})$. b Chain of activated spermatozoa extracted from female. MSP has punctate and fibrillar pattern of distribution in pseudopodia that marked by arrows. Selected area is given in higher magnification (scale bar $10 \mu \mathrm{m}$, magnified area $2 \mu \mathrm{m}$ ). 
a

\section{m f \\ - - - -tubulin}

\section{m f}

\section{$42 \mathrm{kDa}=$}

$-\mathrm{MSP}$ b

\section{peptide}

\section{- +}

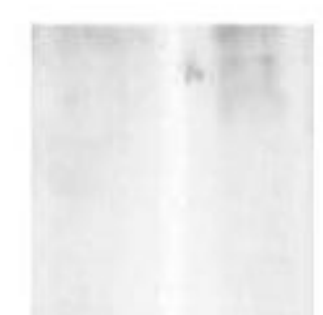

\section{$29 \mathrm{kDa}=$}

\section{$29 \mathrm{kDa}$ -}

\section{Figure 4}

Western blot analysis of MSP in E. brevis. a MSP has unusual mobility in gel and is found as protein with weight 36-38 kDa. Both male and female samples reveal MSP signal, because the latter include inseminated females. a-Tubulin was used as a loading control (approximate weight $55 \mathrm{kDa}$ ). b Peptide competition assay confirms reactivity of anti-MSP antibodies with protein bandof 36-38 kDa. 


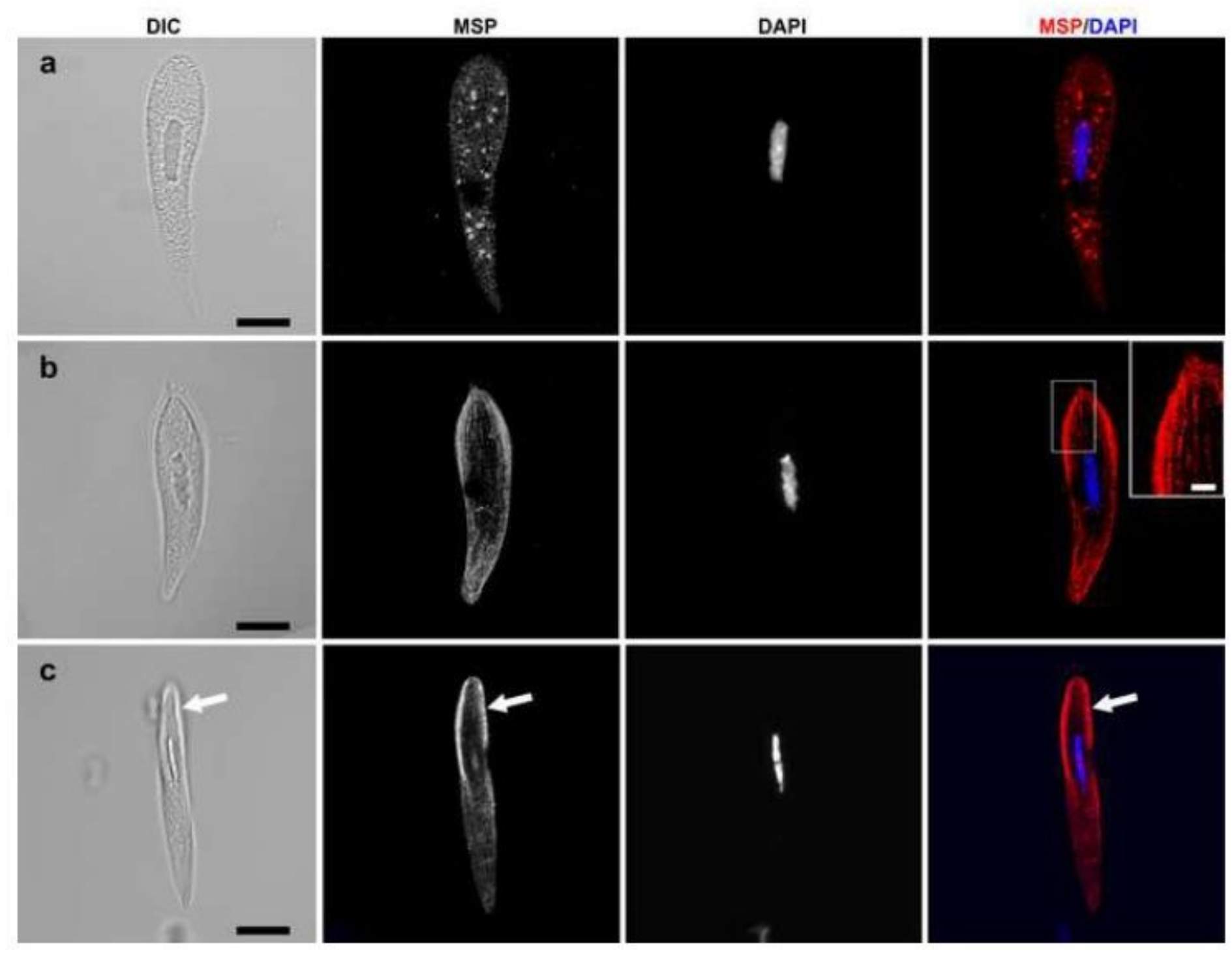

\section{Figure 5}

Immunolocalization of MSP in E. brevis sperm. a Immature spermatozoon from male. MSP concentrates in large granules (scale bar $10 \mu \mathrm{m}$ ). b Spermatozoon recovered from male and partially activated by 10 min incubation in sea water. MSP revealed more diffuse pattern with appearance of longitudinal fibrillar structures. Selected area is given in higher magnification (scale bar $10 \mu \mathrm{m}$, magnified area $2 \mu \mathrm{m}$ ). c Mature spermatozoon from female. Most of MSP signal is found in pseudopod (scale bar $10 \mu \mathrm{m}$ ). 
peptide antigen Pan_g61.t1

Pan_g6018.t1

Pan_g6424-t1

Pan_g9068.t1

Pan_g19433.t1

Pan_g21178.t1

peptide antigen

Pan_g61.t1

Pan_g6018.t1

Pan_g6424.t1

Pan_g9068.t1

Pan_g19433.t1

Pan_g21178.t1
$1-$ - - - I KT T NMKRL GVDPPCGVLDP 1 MAQSVPPGD IGTQPGTK IVFNAPYDDKHTYHIKI TNSGGRR I GWA I KTT NMKRL GVDPPCGVLDP 1 MAQSVPPGD IGTQPGTK IVFNAPYDDKHTYHIKI TNAGGRRI GWA I KT TNMKRL GVDPPCGVLDP 1 MAQSVPPGD I GTQPGTK I VFNAPYDDKHTYHIKI TNSGGRR I GWA I KT T NMKRL GVDPPCGVLDP 1 MAQSVPPGD IGTQPGTK IVFNAPYDDKHTYHIKI TNSGGRR I GWA I KT TNMKRL GVDPPCGVLDP 1 MAQS I PPGD I GTQPGTK IVFNAPYDDKHTYHIKI INSGGRR I GWA I KTT NMKRLGVDPPSGVLDP 1 MAQSVPPGD IGTQPGTKIVFNAPYDDKHTYHIKITNSGGRRIGWA IKTTNMKRLGVDPPCGVLDP

$21 \mathrm{KE}$ 66 KENVLMAVSCDAFDAAAEDTNNDRI T I EWTNTPDGAAKTFRREWFQGDGMVRRKNLP IEYNP 66 KENVLMAVSCDSFKYGEEDTNNDR | T I EWT NTPDGAAKTFRREWFQGDGMVRRKNLP IEYNP 66 KENVLMAVSCDAFDPAAEDTNNDR I T I EWT NTPDGAAKTFRREWFQGDGMVRRKNLP IEYNP 66 KENVLMAVSCDAFKFGEEDTNNDR I T I EWT NTPDGAAKTFRREWFQGDGMVRRKNLP IEYNP 66 KENVLMAVSCDAFQFGQEDTNNDR I T I EWT NTPDGAAKTFRREWFQGDGMVRRKNLP IEYNP 66 KENVLMAVSCDAFKFGEEDTNNDRI T I EWT NTPDGAAKTFRREWFQGDGMVRRKNLP I EYNP

b

peptide antigen MSP124-1 MSP124-2 MSP124-3

peptide antigen MSP124-1 MSP124-2 MSP124-3
1

1... . . . . . . . . . . . . . . . . . . . . . . I KT T NMKRLGVDPPCGVLDPKE 1 MTMPGE I KTQPENKL I FGAPFDAPVTVSLRATNAGGKK I GWA I KT T NMRRF SVEPGMGTMEPKAH 1 MTMPGDVKTQPENKL I FGAPFDAPVTVSLRATNAGGKK I GWA I KT T NMRRFSVEPGMGTMEPKAH 1 MTMPGE I KTQPENKL I FGAPFDAPVTVSLRATNAGGKK | GWA | KTTNMRRFSVEPGMGTMEPKAH

66 VNLSVTCNPFD I GNED I SNDR I I I EWTDTPAGAGDKFQREWFQGSG I IRRKV INCEYNV 66 VNLSVT CNPFD I GNED I SNDR I T I EWTDTPAGAGDKFQREWFQGSG I IRRKV I NCEYNV 66 VNLSVT CNPFD I GNED I SNDR I T I EWTDTPAGAGNKFQREWFQGSG | IRRKV I NCEYNV

\section{Figure 6}

Putative MSPs that are most similar to peptide antigen. a P. redivivus MSPs aligned with peptide antigen. Protein sequences (Pan_g61.t1, Pan_g6018.t1, Pan_g6424.t1, Pan_g9068.t1, Pan_g19433.t1 and Pan_g21178.t1) were found by Blast using peptide antigen as query in WormBase Parasite (https://parasite.wormbase.org). b E. brevis MSPs aligned with peptide antigen. Multiple alignment was performed using ProbCons and visualized in Jalview with BLOSUM62 color scheme. 


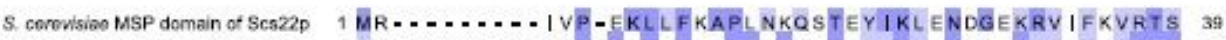
$H$ sapiens MSP domain of VAPA 1 I L - - . - - VL DPPTDL KFKGPFT DVVTTNLKL RNPSDRKVCFKVKTT 41 T psendosphañs 1 MRNE - I PHDI I IEPSTCLFFNGPFDEAKSQSVRMRNPGGQAVAWA I KTN $4 \mathrm{PA}$ T. paptre 1 MRNE - I PHDIT IEPSTCLFFNGPFDETKSQAVRMRNPGGQA IAWA I KTN $\triangle A$ T. nativa 1 MPKP-|PSELKTSPAER IVFNAPFEEKKNYPFSI INNGKEKIAYM I KLS 48 T. thchurg 1 MAKQ-MPAD I KTEPLDKL YFNAPFKEKKNYKIAVTNTGAKPLAWCVKST 48

E. DEVIS MSP124-1 1 MT - -MPGFIKTQPENKL I FGAPFDAPVTVSLRATNAGCKKICWAIKTT 46 E Grenis MSP124-2 1 MT - -MPODVKTQPENKL I FGAPFDAPVTVSLRATNAGGKKIOWAIKTT 4 G

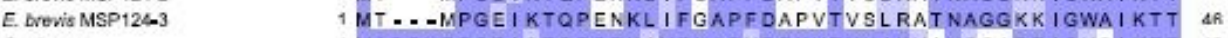
C. ologans 1 MAQSVPPGDIQTQPGTKI VFNAPYDDKHTYHIKVINSSARRIGYGIKTT 49 D. miparus 1 MAS - VPPGDINTQPNSKIVFNAPYDOKHTYHIKII NASGRRIGWAIKTI 4B Prodinus 1 MAQSVPPGDIGTQPGTKIVFNAPYODKHTYHIKITNSGGRRIOWAIKTT 49 S. IGW 1 MAQSVPPODIQTQPGTKIVFNAPYDDKHTYHIKITNSOGRRIOWAIKTT 49 O. voinus 1 MAQSVPPGDI HTQPGSKIVFNAPYDDKHTYHINITNAGGRRIGWAIKTT 49 A. sum 1 MAQSVPPGDINTOPSOK IVFNAPYDDKHTYHIKITNAGGRRIGWA I KTI 49

S. convisian MSP domain of Scs22p 40 APTKYCVRPNVA I I GAHESVNVQ I VFLGLPKSTADDEMDQKRDKFL IVT 8B $H$. sapiens MSP domain of VAPA 42 APRRYCVRPNSO I I DPOSTVTVSVMLQPFOYDPN - - - EKSKHKFMVQT RF T. pseudosphatis 49 NRARLNAEPPGG I LQAGTQIAVN I I SAPVRRAHQVG - -KQESDSIIFEW 95

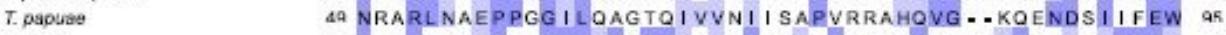
I, nativa 49 NEMRTMCEPSHGVLNPGENIWIRVHLEEFKPTVE. . . NTOPNTLT IEY 93

T. 49 NVSRI SFDPSAGVLDANETFMFTAVTEVFFPTPE - .. NL KODQIT IEW 93 47 NMRRFSVEPGMOTMEPKAHVNL SVTCNPFDIGNE- - - DI SNDRITIEW 91 47 NMRRF SVEPGMGTMEPKAHVNL SVTCNPFDIGNE_... - DI SNDRITIEW 91 47 NMRRFSVEPGMGTMEPKAHVNL SVTCNPFDIGNE. . . DISNDRITIEW 91 50 NMKRLGVDPPCGVLDPKEAVLLAVSCDAFAFGCE - .. DTNNDRITVEW 94 49 NMKRLGVDPACGVLDPKEATLMAVSCDTFEYGRE. . . DTNNDR I TVEW 93 5. NMKRLGVDPPCEVLDPKENVLMAVSCDAFKFGEE... - DTNNDRITIEW 94 50 NMKRLGVDPPCGVLDPKENVLMAVSCDAFKFGEE- - - DTNNDR I T I EW 94
5. NMKRLGVDPPSGVLDPKENVLMAVSCDAFAYGQE- - -DTNNDRI T IEW 94

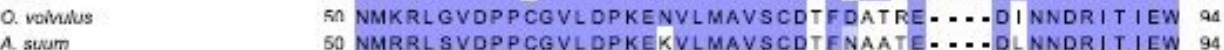

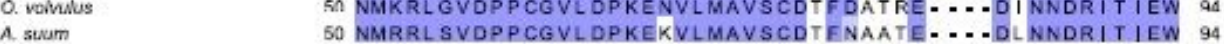

S. cerevisiag MSP domain of Scs22p 8f LP I PAAYQNV - . - . - . - EDGELL SDW

H. sapions MSP domain of VAPA 87 IFAPPNTSDM - - . - . - EAVWKEAKP

QR CQVES - - DIPFSIELLKGDALLRRRKIKI I YNP

98 COVES - - DIPFS IDLLKGDALLRRRKIKIIYNPP

T. nativa

94 CFPPEGSDKNFNPSWERLNVI IRRKHVALEFNA

94 ILAPDGEGRKFNREWMQRQVI VRRKH I TVFYNP

92 TDTPAGAGDKFQREWFQGSGI IRRKV I NCEYNV

9) TDTPAGAGDKFQREWFQGSGI IRRKV INCEYNV

9) TDTPAGAGNKFOREWFOGSGI IRRKV INCEYNV

95 TNTPDGAAKOFRREWFQGDGMVRRKNLPI EYNP

94 CNTPDGAAKQFRREWFQGDGMURRKNLPI EYNP

9.5 TNTPDGAAKTFRREWFQGDGMVRRKNLP I EYN

$\begin{array}{ll}\text { S. rati } & 95 \text { TNTPDGAAKTFRREWFQG OGMVRRKNLP I EYNP } \\ \text { Q. volumus } & \text { 95 TNTPDGAAKOFRREWFQGDGMVRRKNLP I EYNL } \\ \text { A. sium } & 95 \text { INTPDGAAKOFRREWFQG DGMVRRKNLPIEYNL }\end{array}$

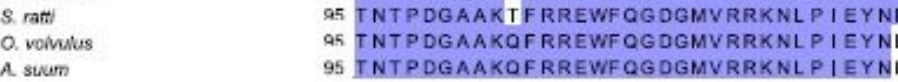

b

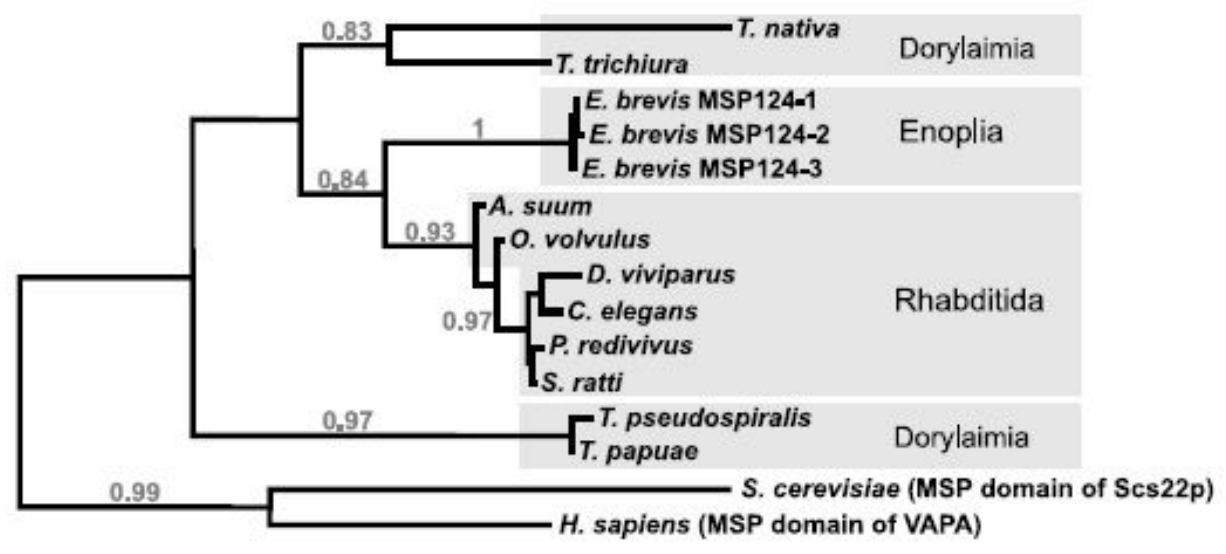

0.6

Figure 7

Multiple alignment and phylogenetic relationships of MSPs. a Multiple alignment of MSPs from 13 taxa of three subclasses of Nematoda. MSPs of six Rhabditida, four Dorylaimia and one Enoplia species were used. Multiple alignment was performed using ProbCons and visualized in Jalview with BLOSUM62 color scheme. MSP sequences of nematodes and MSP domains of Saccharomyces cerevisiae and Homo sapiens used in multiple alignment were downloaded from following databases, GenBank 
(https://www.ncbi.nlm.nih.gov) (A. suum: CAA63933.1, Dictyocaulus viviparus: AAB27962.2, Strongyloides ratti: XP_024503659.1, Trichuris trichiura: CDW57515.1, Trichinella nativa: OUC40810.1, Trichinella pseudospiralis: KRX99722.1, Trichinella papuae: KRZ74366.1, S. cerevisiae MSP domain of Scs22p: AJP97989.1), WormBase Parasite (https://parasite.wormbase.org) (P. redivivus: Pan_g9068.t1) and UniProt (https://www.uniprot.org) (C. elegans: P53017, Onchocerca volvulus: P13262.3, H. sapiens MSP domain of VAPA: Q9P0L0). b Maximum likelihood 571 tree with SH-aLRT branch support.

Only significant values $(\geq 0.8)$ are shown. MSP domains of S. cerevisiae (Scs22p) and H. sapiens (VAPA) proteins were chosen as an outgroup. 